\title{
Constraining frequency-magnitude-area relationships for rainfall and flood discharges using radar-derived precipitation estimates: example applications in the Upper and Lower Colorado River basins, USA
}

\author{
Caitlin A. Orem and Jon D. Pelletier \\ Department of Geosciences, The University of Arizona, 1040 E. 4th Street, Tucson, AZ 85721, USA \\ Correspondence to: Caitlin A. Orem (oremc@email.arizona.edu)
}

Received: 5 October 2015 - Published in Hydrol. Earth Syst. Sci. Discuss.: 10 November 2015

Revised: 15 September 2016 - Accepted: 16 September 2016 - Published: 8 November 2016

\begin{abstract}
Flood-envelope curves (FECs) are useful for constraining the upper limit of possible flood discharges within drainage basins in a particular hydroclimatic region. Their usefulness, however, is limited by their lack of a well-defined recurrence interval. In this study we use radar-derived precipitation estimates to develop an alternative to the FEC method, i.e., the frequency-magnitude-area-curve (FMAC) method that incorporates recurrence intervals. The FMAC method is demonstrated in two well-studied US drainage basins, i.e., the Upper and Lower Colorado River basins (UCRB and LCRB, respectively), using Stage III Next-GenerationRadar (NEXRAD) gridded products and the diffusion-wave flow-routing algorithm. The FMAC method can be applied worldwide using any radar-derived precipitation estimates. In the FMAC method, idealized basins of similar contributing area are grouped together for frequencymagnitude analysis of precipitation intensity. These data are then routed through the idealized drainage basins of different contributing areas, using contributing-area-specific estimates for channel slope and channel width. Our results show that FMACs of precipitation discharge are power-law functions of contributing area with an average exponent of $0.82 \pm 0.06$ for recurrence intervals from 10 to 500 years. We compare our FMACs to published FECs and find that for wet antecedent-moisture conditions, the 500-year FMAC of flood discharge in the UCRB is on par with the US FEC for contributing areas of $\sim 10^{2}$ to $10^{3} \mathrm{~km}^{2}$. FMACs of flood discharge for the LCRB exceed the published FEC for the LCRB for contributing areas in the range of $\sim 10^{3}$ to $10^{4} \mathrm{~km}^{2}$. The FMAC method retains the power of the FEC
\end{abstract}

method for constraining flood hazards in basins that are ungauged or have short flood records, yet it has the added advantage that it includes recurrence-interval information necessary for estimating event probabilities.

\section{Introduction}

\subsection{Flood-envelope curves}

For nearly a century, the flood-envelope curves (FECs), i.e., curves drawn slightly above the largest measured flood discharges on a plot of discharge vs. contributing area for a given hydroclimatic region (Enzel et al., 1993), have been an important tool for predicting the magnitude of potential future floods, especially in regions with limited stream-gauge data. FECs assume that, within a given hydroclimatic region, maximum flood discharges for one drainage basin are similar to those of other drainage basins of the same area, despite differences in relief, soil characteristics, slope aspect, etc. (Enzel et al., 1993). This assumption enables sparse and/or short-duration flood records over a hydroclimatic region to be aggregated in order to provide more precise constraints on the magnitude of the largest possible (i.e., long-recurrenceinterval) floods.

FECs reported in the literature have a broadly similar shape across regions of widely differing climate and topography. For example, FECs for the Colorado River Basin (Enzel et al., 1993), the central Appalachian Mountains (Miller, 1990; Morrison and Smith, 2002), the 17 hydrologic regions 
within the US defined by Crippen and Bue (1977), the US as a whole (Costa, 1987; Herschy, 2002), and China (Herschy, 2002) are all concave-down when plotted in log-log space, with maximum recorded flood discharges following a powerlaw function of contributing area for small contributing areas and increasing more slowly at larger contributing areas (i.e., the curve "flattens").

Traditional FECs also have the potential problem that the maximum flood associated with smaller drainage basins may be biased upward (or the floods of larger drainage basins biased downward) because there are typically many more records of floods in smaller drainage basins relative to larger drainage basins (because there are necessarily fewer large drainage basins in any hydroclimatic region). That is, the largest flood on record for small drainage basins within a hydroclimatic region likely corresponds to a flood of a larger recurrence interval compared with the largest flood on record for larger drainage basins. In this paper we present a method that includes recurrence-interval information and avoids any sample-size bias that might exist as a function of contributing area.

The use of FECs to quantify flood regimes is limited by the lack of recurrence-interval information (Wolman and Costa, 1984; Castellarin et al., 2005) and by the short length, incomplete nature, and sparseness of many flood discharge records. Without recurrence-interval information, the data provided by FECs are difficult to apply to some research and planning questions related to floods. In the US for example, the 100and 500-year flood events are the standard event sizes that define flood risk for land planning and engineering applications (FEMA, 2001).

Previously published studies have looked at new approaches to approve upon the FEC method. Castellarin et al. (2005) took a probabilistic approach to estimating the exceedance probability of the FEC for synthetic flood data. The authors were able to relate the FECs of certain recurrence intervals to the correlation between sites, the number of flood observations, and the length of each observation. Later, Castellarin (2007) and Castellarin et al. (2009) applied these methods to real flood record data and extreme rainfall events for basins within northern-central Italy. Castellarin et al. (2009) also created depth-duration envelope curves of precipitation to relate extreme precipitation events to mean annual precipitation. This group of studies was successful in incorporating recurrence-interval information into the traditional FEC method. However, most of the models presented in these studies were completed with synthetic data or created for design storm processes and require additional analysis. Also, most of the precipitation data used in these past studies were collected using rain gauges (point sources), while only a small subset of data in Castellarin et al. (2009) was sourced from radar-derived precipitation estimates. In contrast to these studies we formulate a simplified method (i.e., the FMAC method) that is readily applicable to any region of interest and can be directly compared to already exist- ing FECs. Also, we favor the use of spatially complete radarderived precipitation estimates in order to apply our methods to ungauged basins.

To mitigate the uncertainty caused by short and incomplete flood discharge records, this study uses a space-for-time substitution (e.g., regionalization) to lengthen the record for a given contributing area. Previous studies have employed similar methods, including the index-flood procedure first described by Dalyrymple (1960) and expanded upon by many subsequent authors. The index-flood method uses data from multiple sites within a region to construct more accurate flood-quantile estimates than would be possible using a single site (Stedinger et al., 1993; Hosking and Wallis, 2005). This method can also be used on precipitation data, where it is referred to as the station-year method (Buishand, 1991). The index-flood method is based on two major assumptions: (1) that observations from two or more basins are independent; and (2) that observations follow the same distribution (Wallis et al., 2007).

Here we use a regionalization method similar to the indexflood method in order to calculate rainfall-intensity values associated with specific recurrence intervals. The assumption of statistical independence of rainfall (and associated flood) observations is one that we assume in this study but understand may not be true for all samples in our natural dataset. This assumption is difficult to definitively prove with natural data (Hosking and Wallis, 2005). For example, a large rainfall event may affect two basins in a similar way and therefore create correlated maximum rainfall-intensity values. This spatial correlation is difficult to avoid and may cause biased results. However, it has been shown that the index-flood method can be used in the absence of fully statistically independent observations and still give robust results (Hosking and Wallis, 1988; Hosking and Wallis, 2005). The assumption that observations are sampled from the same distribution is also somewhat difficult to prove with natural data, but by knowing the study areas well a researcher can identify regions with similar rainfall and flood mechanisms. Many examples of this type of area analysis can be found in the literature, including Soong et al. (2004), who separated rural streams in Illinois into hydrological regions based on basin morphology and soil characteristics. Soong et al. (2004) used regionalization in their study to increase the amount of flood data available for frequency analysis. Wallis et al. (2007) employed a similar regionalization method to identify hydroloclimatic regions in their study of precipitation frequency in Washington. It should be noted that FECs in general use this type of regionalization approach to analyze maximum flood data for hydroclimatic regions with similar flood mechanisms. In this study we similarly attempt to analyze regions based on their basic rainfall mechanisms, in this case by separating the Upper and Lower Colorado River basins.

In this study, a new method for estimating flood discharges associated with user-specified recurrence intervals 
is introduced that uses radar-derived precipitation estimates (in this case rainfall only), combined with the diffusion-wave flow-routing algorithm, to create frequency-magnitude-area curves (FMACs) of flood discharge. Our method (i.e., the FMAC method) retains the power of the FEC approach in that data from different drainage basins within a hydroclimatic region are aggregated by contributing area, thereby enabling large sample sizes to be obtained within each contributing-area class in order to more accurately constrain the frequencies of past extreme flood events and hence the probabilities of future extreme flood events within each class. The method improves upon the FEC approach in that the complete spatial coverage of radar-derived precipitation estimates provides for large sample sizes of most classes of contributing area (larger contributing areas have fewer samples). The radar-derived precipitation estimates include only rainfall and therefore snow and other types of precipitation are not included in the study. The precipitation estimates are then used to predict flood discharges associated with specific recurrence intervals by first accounting for water lost to infiltration and evapotranspiration using runoff coefficients appropriate for different contributing areas and antecedentmoisture conditions, and then routing the available water using a flow-routing algorithm. Predicted flood discharges are presented as FMACs on log-log plots, similar to traditional FECs, except that the method predicts a family of curves, one for each user-defined recurrence interval. These plots are then compared to FECs for the study region (Enzel et al., 1993) and the US (Costa, 1987).

\subsection{Study area}

This study focuses on the Upper and Lower Colorado River basins (UCRB and LCRB, respectively; Fig. 1) as example applications of the FMAC method. Although the methods we develop are applied to the UCRB and LCRB in the western US in this study, the methods are applicable to any region of interest where radar-derived precipitation estimates are available (i.e., the entire US and at least 22 countries around the world; Li, 2013; RadarEU, 2014). We focus on the UCRB and LCRB because they have been a focus of floodhazard assessment studies in the western US and hence the FECs available for them are of especially high quality. In addition, the distinctly different hydroclimatic regions of the UCRB and LCRB (Sankarasubramanian and Vogel, 2003) make working in these regions an excellent opportunity to test and develop the new methods of this study on different precipitation patterns and storm types.

Precipitation and flooding in the LCRB are caused by convective-type storms, including those generated by the North American Monsoon (NAM), and frontal-type and tropical storms sourced from the Pacific Ocean and the Gulf of California (House and Hirschboeck, 1997; Etheredge et al., 2004). In the UCRB, the influence of the NAM and tropical storms is diminished and floods are generally caused by

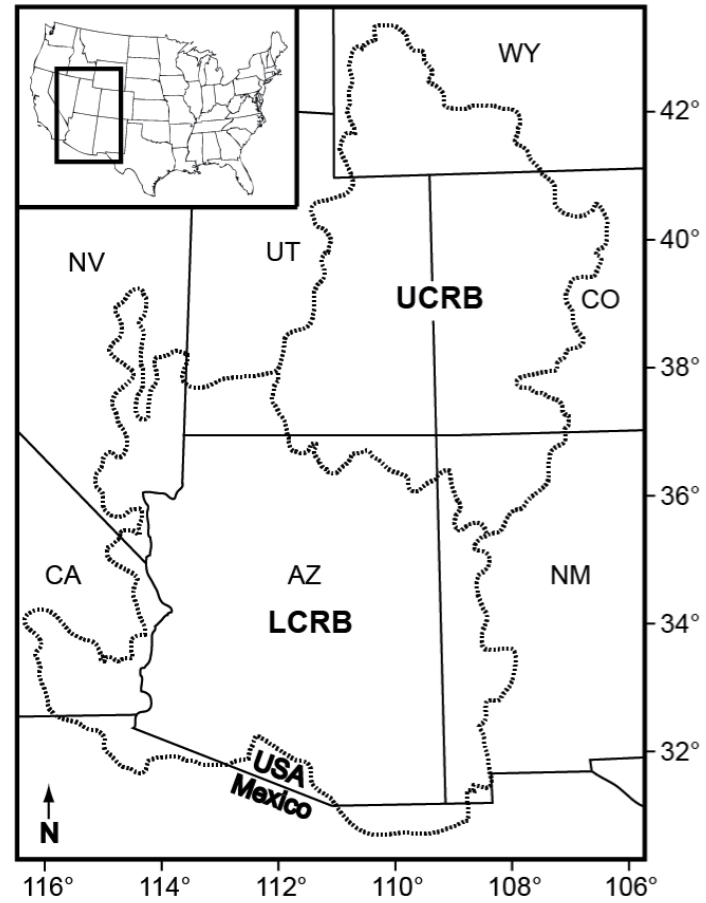

Figure 1. Map showing the locations of the Upper and Lower Colorado River basins (UCRB and LCRB, respectively) outlined by the dotted line.

Pacific frontal-type storms (Hidalgo and Dracup, 2003). In both regions, the El Niño-Southern Oscillation (ENSO) alters the frequency and intensity of the NAM, tropical storms, and the Pacific frontal systems, and can cause annual variations in precipitation and flooding (House and Hirschboeck, 1997; Hidalgo and Dracup, 2003). Winter storms in both regions are also intensified by the occurrence of atmospheric rivers (Dettinger et al., 2011), which can cause total winter precipitation to increase up to approximately $25 \%$ (Rutz and Steenburgh, 2012). The radar-derived precipitation estimates used in this study record this natural variability in precipitation in the two regions.

The methods used in this study to calculate rainfall and flood discharges of specified recurrence intervals from radarderived precipitation estimates require a few main assumptions. The first assumption is that of climate stationarity; i.e., the parameters that define the distribution of floods do not change through time (Milly et al., 2008). Climate is changing and these changes pose a challenge to hazard predictions based on the frequencies of past events. Nevertheless, stationarity is a necessary assumption for any probabilistic analysis that uses past data to make future predictions. The results of such analyses provide useful starting points for more comprehensive analyses that include the effects of future climate changes. The second assumption is that the sample time interval is long enough to correctly represent the current hydroclimatic state (and its associated precipita- 
tion patterns and flood magnitudes and risks) of the specified study area. Our study uses data for the 1996 to 2004 water years and therefore may be limited by inadequate sampling of some types of rare weather patterns and climate fluctuations within that time interval. To address whether or not the sample time interval used in this study includes major changes in circulation and weather patterns, and therefore is a good representation of climate in the CRB, we investigated the effect of the ENSO on rainfall intensity within the UCRB and LCRB. ENSO is a well-known important influence on the hydroclimatology of the western US (Hidalgo and Dracup, 2003; Cañon et al., 2007). In general, winter precipitation in the southwestern US increases during El Niño events and decreases during La Niña events (Hidalgo and Dracup, 2003). The opposite effects are found in the northwestern portions of the US (including the UCRB; Hidalgo and Dracup, 2003). The last assumption of the method is that all basins of similar contributing area respond similarly to input rainfall, i.e., that they have similar flood-generating and flow-routing mechanisms. Specifically, the method assumes that basins of similar contributing area have the same runoff coefficient, flow-routing parameters, basin shape, and channel length, width, and slope. This assumption is necessary in order to aggregate data into discrete contributing-area classes so that the frequency of extreme events can be estimated from relatively short-duration records. In this study, high-recurrence-interval events (i.e., low-frequency events) can be considered despite the relatively short length of radarderived-precipitation-estimate records because the number of samples in the radar-derived record is extremely large, especially for small contributing areas and short-duration floods. For example, for a $1 \mathrm{~h}$ time-interval-of-measurement and a contributing area of $4096 \mathrm{~km}^{2}$ event in the UCRB, there are approximately 40 (number of spatial-scale samples) times 55000 (number of temporal-scale samples in 9 years of data) samples of rainfall-intensity values (and associated modeled discharges obtained via flow routing). As contributing area and time intervals of measurement increase there are successively fewer samples, within any particular hydroclimatic region, thus increasing the uncertainty of the resulting probability assessment for larger areas and longer time periods.

\section{Next-Generation-Radar (NEXRAD) data}

The specific radar-derived precipitation estimates we use in this study come from the Stage III Next-GenerationRadar (NEXRAD) gridded product, which is provided for the entire US, Guam, and Puerto Rico. NEXRAD was introduced in 1988 with the introduction of the Weather Surveillance Radar 1988 Doppler, or WSR-88D, network (Fulton et al., 1998). The WSR-88D radars use the Precipitation Processing System (PPS), a set of automated algorithms, to produce precipitation intensity estimates from reflectivity data.
Reflectivity values are transformed to precipitation intensities through the empirical $Z-R$ power-law relationship

$Z=\alpha R^{\beta}$

where $Z$ is precipitation rate $\left(\mathrm{mm} \mathrm{h}^{-1}\right), \alpha$ and $\beta$ are derived empirically and can vary depending on location, season, and other conditions (Smith and Krajewski, 1993), and $R$ is reflectivity $\left(\mathrm{mm}^{6} \mathrm{~m}^{-3}\right.$; Smith and Krajewski, 1993; Fulton et al., 1998; Johnson et al., 1999). Precipitation intensity data are filtered and processed further to create the most complete and correct product (Smith and Krajewski, 1993; Smith et al., 1996; Fulton et al., 1998; Baeck and Smith, 1998). Further information and details about PPS processing are thoroughly described by Fulton et al. (1998).

Stage III NEXRAD gridded products are Stage II precipitation products mapped onto the Hydrologic Rainfall Analysis Project (HRAP) grid (Shedd and Fulton, 1993). Stage II data are hourly precipitation intensity products that incorporate both radar reflectivity and rain-gauge data (Shedd and Fulton, 1993) in an attempt to make the most accurate precipitation estimates possible. The HRAP grid is a polar coordinate grid that covers the conterminous US, with an average grid size of $4 \mathrm{~km}$ by $4 \mathrm{~km}$, although grid size varies from approximately $3.7 \mathrm{~km}$ (north to south) to $4.4 \mathrm{~km}$ (east to west) in the southern and northern US, respectively (Fulton et al., 1998).

\section{Methods}

\subsection{NEXRAD data conversion and sampling}

NEXRAD Stage III gridded products (hereafter NEXRAD products) for an area covering the Colorado River Basin from 1996 to 2005 were downloaded from the NOAA HDSG website (http://dipper.nws.noaa.gov/hdsb/data/nexrad/cbrfc_ stageiii.php) for analysis. The data files were converted from archived XMRG files to ASCII format (each data file representing the mean rainfall intensity within each $1 \mathrm{~h}$ interval) using the xmrgtoasc.c program provided on the NOAA HDSG website. The ASCII data files were then input into a custom program written in IDL for analysis.

\subsection{Rainfall sampling over space}

In this study we quantified hourly rainfall intensities $\left(\mathrm{mm} \mathrm{h}^{-1}\right)$ over square idealized drainage basins (i.e., not real drainage basins, but square drainage basins as shown schematically in Fig. 2a as brown squares) of a range of areas from 16 to $11664 \mathrm{~km}^{2}$ (approximately the contributing area of the Bill Williams River, AZ, for readers familiar with the geography of the western US) by successively spatially averaging rainfall-intensity values at HRAP pixel-length scales of powers of 2 (e.g., 4, 16 pixel $^{2}$ ) and 3 (e.g., 9, 81 pixel $^{2}$; Fig. 2, Step 1). Spatial averaging is done by both powers of 2 and 3 


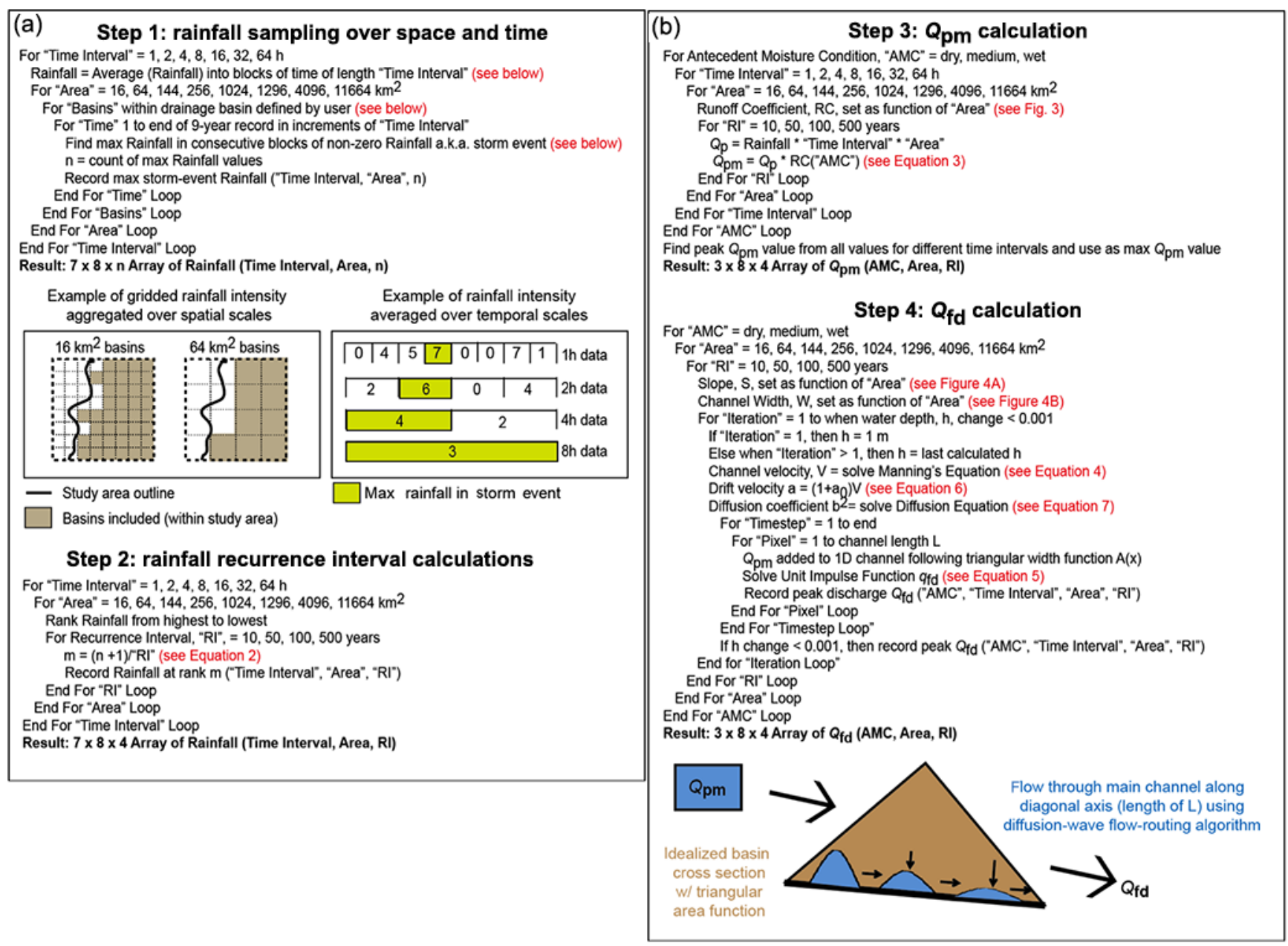

Figure 2. (a) Pseudocode describing the methods of the paper with schematic diagrams shown below pseudocode in some cases. Equations within the text and other figures are referenced in red text. (b) Pseudocode describing the methods of the paper with schematic diagrams shown below pseudocode in some cases. Equations within the text and other figures are referenced in red text.

simply to include more points on the FMACs than would result from using powers of 2 or 3 alone. The number of samples within each contributing area class limited the range of contributing areas used in this study; i.e., at larger contributing areas there were too few samples to successfully apply the frequency analysis.

UCRB and LCRB boundaries from GIS hydrologic unit layers created by the USGS and provided online through the National Atlas site (http://gdg.sc.egov.usda.gov) were projected to HRAP coordinates using the methods of Reed and Maidment (2006). These boundaries were used to delineate the region from which rainfall data were sampled from the NEXRAD products; i.e., when averaging rainfall data by powers of 2 and 3, a candidate square drainage basin was not included in the analysis if any portion of the square fell outside of the boundaries of the UCRB or LCRB (Fig. 2a). Throughout the analysis, the HRAP pixel size was approximated by a constant $4 \mathrm{~km}$ by $4 \mathrm{~km}$ size despite the fact that
HRAP pixel sizes vary slightly as a function of latitude (Reed and Maidment, 2006). Our study's drainage basins span latitudes between approximately 31 and $43^{\circ} \mathrm{N}$, resulting in a maximum error of $15 \%$. However, by keeping the pixel size constant, all pixels could be treated as identical in size and shape, allowing us to sample the NEXRAD products in an efficient and automated way over many spatial scales.

For larger contributing areas, necessarily fewer samples are available within a given hydroclimatic region, thus increasing the uncertainty associated with the analysis for those larger contributing-area classes. For the UCRB and LCRB specifically, the uncertainty in the analysis becomes significant for contributing-area classes equal to and larger than $\sim 10^{3}$ to $10^{4} \mathrm{~km}^{2}$, depending on the recurrence interval being analyzed. Of course, if the hydroclimatic region is defined to be larger, more samples are available for each contributingarea class and hence larger basins can be analyzed with confidence. 


\subsection{Rainfall sampling over time}

In addition to computing rainfall intensities as a function of spatial scale, we averaged rainfall intensities as a function of the time interval of measurement ranging from 1 to $64 \mathrm{~h}$ in powers of 2 by averaging hourly rainfall-intensity records over the entire 9-year study period (Fig. 2, Step 1). This range in time intervals was chosen in order to capture rainfall events that last on the order of $\sim 1 \mathrm{~h}$ (convective-type storms) to days (frontal-type storms).

Rainfall data were sampled temporally by taking the maximum value of each storm event. Storm events were identified as consecutive non-zero rainfall-intensity values separated by instances of zero values in time for each temporal scale. This allows for multiple maximum rainfall values in time to be sampled within a year and throughout the entire 9-year study period. This sampling method is similar to that used in the peak over threshold (POT) method typically used on discharge data where a minimum threshold value is set and maximum peaks above the threshold value are recorded as maximum events. Here we set the minimum threshold value to zero, and hence the maximum values of all individual storm events are considered in the analysis.

\subsection{Rainfall recurrence-interval calculations}

To determine the rainfall-intensity values with a userspecified recurrence interval, maximum rainfall intensities of storm events sampled from the NEXRAD data for each contributing-area and time-interval-of-measurement class were first ranked from highest to lowest (Fig. 2a, Step 2). The relationship between recurrence intervals and rank in the ordered list is given by the probability-of-exceedance equation (i.e., the frequency-rank relationship):

$\mathrm{RI}=\frac{(n+1)}{m}$,

where $\mathrm{RI}$ is the recurrence interval ( $\mathrm{yr})$, defined as the inverse of frequency $\left(\mathrm{yr}^{-1}\right)$ or probability of exceedance, $n$ is the total number of samples in each contributing area and timeinterval-of-measurement scaled to units in years (resulting in units of yr), and $m$ is the rank of the magnitude ordered from largest to smallest (unitless). Here the recurrence interval is prescribed $(10,50,100$, and 500 years); then, the rank associated with this recurrence interval is computed using the frequency-rank relationship (Eq. 2). The resulting rainfall intensities associated with a user-specified recurrence interval and contributing-area and time-interval-of-measurement class were then used to calculate the $Q_{\mathrm{p}}$ value.

At the end of the calculations described above we have datasets of rainfall-intensity values for each combination of the eight contributing-area classes, the seven time-intervalof-measurement classes, and the four recurrence intervals. We then find the maximum values of rainfall intensity associated with a given contributing-area class and recurrence interval among all values of the time-interval-of-measurement class (i.e., the values calculated for 1 to $64 \mathrm{~h}$ time intervals). This step is necessary in order to find the maximum values for a given contributing area class and recurrence interval independent of the time-interval-of-measurement, i.e., independent of storm durations and associated types of storms. The maximum values are used to be consistent with the methods of the traditional FECs where the points represent the largest possible storm for a given contributing area. These maximum values are used to calculate $Q_{\mathrm{p}}$ and $Q_{\mathrm{fd}}$ (see next section).

\subsection{Rainfall and runoff calculations}

The first variable calculated from the maximum rainfall intensities found for each contributing-area class and recurrence interval is the precipitation (here rainfall only) discharge, $Q_{\mathrm{p}}$. The variable $Q_{\mathrm{p}}$ is defined as the average rainfall intensity over a basin and time interval of measurement multiplied by the contributing area, resulting in units of $\mathrm{m}^{3} \mathrm{~s}^{-1}$. This is a simple calculation resulting in a "discharge" of rainfall to a basin. $Q_{\mathrm{p}}$ is the input value for the flow-routing algorithm that we employ to calculate the peak flood discharge (Fig. 2b, Step 3).

The flow-routing algorithm we employ does not explicitly include infiltration and other losses that can further reduce peak flood discharge relative to input to the basin, $Q_{\mathrm{p}}$. In this study we modeled infiltration and evaporation losses by simply removing a volume of water per unit time equal to one minus the runoff coefficient, i.e., the ratio of runoff to rainfall over a specified time interval, for three antecedentmoisture scenarios (wet, med, and dry). We estimated runoff coefficients for each contributing-area class and each of three antecedent-moisture scenarios using published values for annual runoff coefficients for large basins within the UCRB and LCRB (Rosenburg et al., 2013) and published values for event-based runoff coefficients for small basins modeled with a range of antecedent-moisture conditions by Vivoni et al. (2007) (Fig. 3). On average, estimated runoff coefficients are higher for smaller and/or initially wetter basins. We found the dependence of runoff coefficients on contributing area and antecedent moisture to be similar despite the large difference in timescales between event-based and annual values. Despite the difference in geographic region between our study site and that of Vivoni et al. (2007) (they studied basins in Oklahoma), the runoff coefficients they estimated are likely to be broadly applicable to the LCRB and UCRB given that basin size and antecedent moisture are the primary controls on these values (climate and soil types play a lesser role except for extreme cases).

We applied the estimated runoff coefficients for all three antecedent-moisture scenarios by simply using them to remove a portion of the $Q_{\mathrm{p}}$ calculated for a specific time interval and basin area:

$Q_{\mathrm{pm}}=C \cdot Q_{\mathrm{p}}$, 


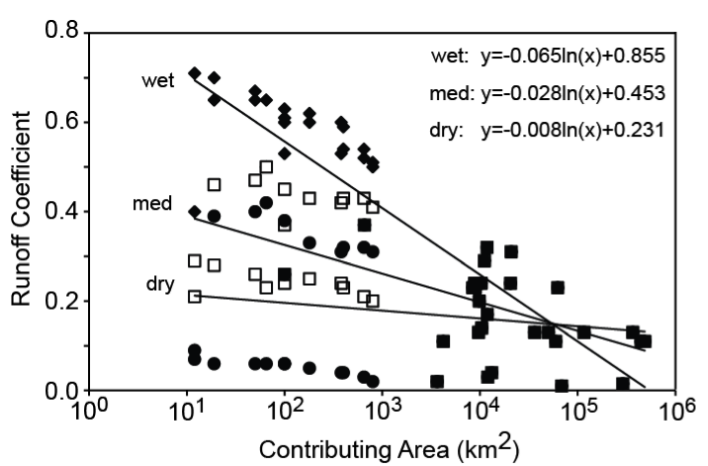

Figure 3. Logarithmic relationships between runoff coefficients and contributing area using modeled data for wet (filled diamonds), medium (open squares), and dry (filled circles) antecedent-moisture conditions (Vivoni et al., 2007) and measured data for larger contributing areas (filled squares; Rosenburg et al., 2013). The medium (open squares) and dry (filled circles) data separate into two distinct groups relating to the precipitation event used to model them, with the lower group and higher group relating to a $12 \mathrm{~h}, 1 \mathrm{~mm} \mathrm{~h}^{-1}$ event and $1 \mathrm{~h}, 40 \mathrm{~mm} \mathrm{~h}^{-1}$ event, respectively. All points were used in the least-squares weighed-regression analysis.

where $C$ is the runoff coefficient calculated for the specific basin area and antecedent-moisture scenario under evaluation. The newly formed $Q_{\mathrm{pm}}$ is now the $Q_{\mathrm{p}}$ value for the wet, medium, or dry antecedent-moisture scenario under analysis for each given recurrence-interval and contributing-area class.

\subsection{Flood discharge calculations}

The second variable calculated in this study, and the endresult of our methods, is the peak flood discharge, $Q_{\mathrm{fd}}$. The variable $Q_{\mathrm{fd}}$ is the peak flood discharge $\left(\mathrm{m}^{3} \mathrm{~s}^{-1}\right)$ calculated via the diffusion-wave flow-routing algorithm for a hypothetical flood triggered by a rainfall discharge, $Q_{\mathrm{pm}}$, input uniformly over the time interval of measurement to idealized square basins associated with each contributing-area class (Fig. 2b, Step 4).

The flow-routing algorithm routes flow along the mainstem channel of idealized square basins with sizes equal to the contributing area of each contributing-area class. The choice of a square basin is consistent with the square sample areas (see Sect. 3.1) and it allows for basin shape to remain the same (and therefore comparable) over the range of contributing areas used in this study. The main-stem channel, with a length of $L(\mathrm{~m})$, was defined as the diagonal distance from one corner to the opposite corner across the square basin (i.e., $L$ is equal to the square root of 2 times the area of the square basin). This main-stem channel was used in conjunction with a normalized area function to represent the shape of the basin and the routing of runoff through the drainage basin network. By including the normalized area function, we can account for geomorphic dispersion (i.e., the attenuation of the flood peak due to the fact that rainfall that falls on the landscape will take different paths to the outlet and hence reach the outlet at different times) in our analyses. The normalized area function, $A(x)$ (unitless), is defined as the portion of basin area, $A_{\mathrm{L}}(x)\left(\mathrm{m}^{2}\right)$, that contributes flow to the main-stem channel within a given range of distances $(x)$ from the outlet, normalized by the total basin area, $A_{\mathrm{T}}\left(\mathrm{m}^{2}\right.$; Mesa and Mifflin, 1986; Moussa, 2008). The normalized area function is assumed to be triangular in shape, with a maximum value at the midpoint of the main-stem channel from the outlet. Area functions, and related width functions, from real basins used in other studies show this triangular shape in general (Marani et al., 1994; Rinaldo et al., 1995; Veneziano et al., 2000; Rodriguez-Iturbe and Rinaldo, 2001; Puente and Sivakumar, 2003; Saco and Kumar, 2008), although not all basins show this shape. The triangular area function has been shown to approximate the average area function of basins and that the peak discharge and time to peak discharge is likely more important to the shape of the flood wave (Henderson, 1963; Rodriguez-Iturbe and Valdes, 1979).

A one-dimensional channel with simplified width and along-channel slope appropriate for channels in the CRB is used to approximate the geometry of the main-stem channel of the idealized basin in the flow-routing algorithm. In addition, values for channel slope, $S\left(\mathrm{~m} \mathrm{~m}^{-1}\right)$, and channel width, $w(\mathrm{~m})$, are assigned based on the contributing area of the idealized basin and the results of a least-squares regression to channel-slope and channel-width data from the CRB. We assume here that the assigned channel slopes and widths represent the average value for the entire idealized basin. To find the best approximations for channel slope and width values, we developed formulae that predict average channel slope and channel width as a function of contributing area based on a least-squares fit of the logarithms of slope, width, and contributing area based on approximately 100 sites in the Colorado River Basin (CRB; Fig. 4). The data used in these leastsquares regressions included slope, width, and contributing area information from all sites in the LCRB and southern UCRB presented in Moody et al. (2003) and additional sites from USGS stream-gauge sites from across the CRB.

The assigned channel slope and width values, together with the values of $Q_{\mathrm{pm}}$ modified for each antecedentmoisture scenario, were used to calculate the depth-average velocities, $V\left(\mathrm{~m} \mathrm{~s}^{-1}\right)$, in hypothetical one-dimensional mainstem channels of idealized square drainage basins corresponding to each contributing-area and time-interval-ofmeasurement class. In this study, flow velocity is not modeled over space and time, but rather is set at a constant value appropriate for the peak discharge using an iterative approach that solves for the peak depth-averaged flow velocity, uses that velocity to compute the parameters of the diffusionwave-routing algorithm, routes the flow, and then computes an updated estimate of peak depth-averaged velocity. To calculate the depth-averaged velocity, $V$, we used Manning's 

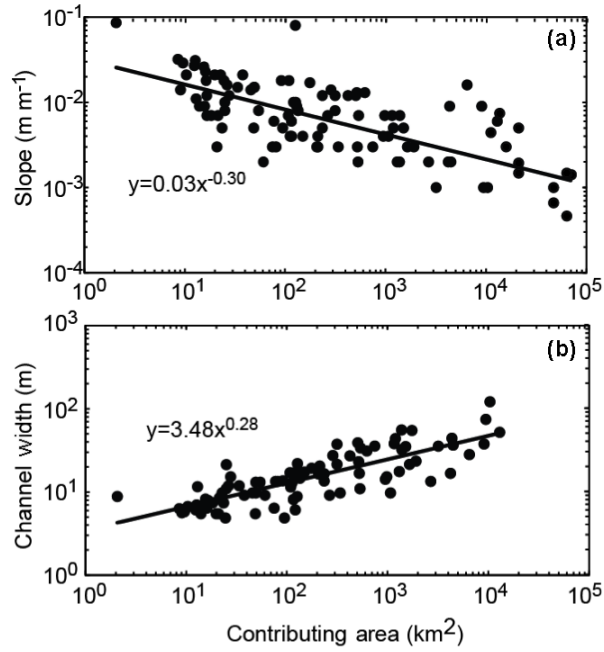

Figure 4. Power-law relationships between channel slope and contributing area (a) and channel width and contributing area (b) for the Colorado River Basin.

equation, i.e.,

$V=\frac{1}{n_{\mathrm{M}}} R^{\frac{2}{3}} S^{\frac{1}{2}}$,

where $n_{\mathrm{M}}$ is Manning's $\mathrm{n}$ (assumed to be equal to 0.035), $R$ is the hydraulic radius $(\mathrm{m})$ calculated with the assigned channel width, and $S\left(\mathrm{~m} \mathrm{~m}^{-1}\right)$ is the assigned channel slope. In order to calculate $R$, the water depth, $h$, of the peak discharge needed to be determined. In this study $h$ was iteratively solved for based on the peak-flow conditions (i.e., the depth-averaged velocity, $V$, associated with the peak-flood discharge, $\left.Q_{\mathrm{fd}}\right)$ with $h$ set at $1 \mathrm{~m}$ for the first calculation of the flow-routing algorithm. At the end of each calculation, $h$ is recalculated using Manning's equation. These iterations continue until the water depth converges on a value (i.e., the change from the last calculation of $h$ to the next calculation of $h$ is $\leq 0.1 \mathrm{~m}$ ) corresponding to a specific recurrence interval, contributing-area class, and time-intervalof-measurement class.

The method we used to model flow through the main-stem channel is the diffusion-wave flow-routing algorithm. This approach is based on the linearized Saint-Venant equations for shallow-water flow in one dimension. To find a simpler, linear solution to Saint-Venant equations, Brutsaert (1973) removed the acceleration term from the equations, leaving the diffusion and advection terms that often provide a reasonable approximation for watershed runoff modeling (Brutsaert, 1973). Leaving the diffusion term in the flow-routing algorithm includes hydrodynamic dispersion of the flood wave in the calculation of the flood hydrograph. In the case where the initial condition is given by a unit impulse function (Dirac function), the cell response function of the channel, $q_{\mathrm{d}}$ (units of $\mathrm{s}^{-1}$ ), is given by

$q_{\mathrm{d}}=\frac{x}{(2 \pi)^{1 / 2} b t_{r}^{3 / 2}} \exp \left[-\frac{\left(a-a t_{r}\right)^{2}}{2 b^{2} t_{r}}\right]$,

where $x$ is the distance along the channel from the location where the impulse is input to the channel, $t_{r}$ is the time since the impulse was input into the channel, and the drift velocity $a\left(\mathrm{~m} \mathrm{~s}^{-1}\right)$ and diffusion coefficient $b^{2}\left(\mathrm{~m}^{2} \mathrm{~s}^{-1}\right)$ are defined as

$a=\left(1+a_{0}\right) V$,

$b^{2}=\frac{V^{3}}{g S F r^{2}}\left(1-a_{0}^{2} F r^{2}\right)$,

where $\mathrm{Fr}$ is the Froude number, $g$ is the acceleration due to gravity ( $\mathrm{m} \mathrm{s}^{-2}$ ), and $a_{0}$ is a constant equal to $2 / 3$ when using Manning's equation (Troch et al., 1994). The large floods modeled in this study are assumed to have critical-flow conditions, and therefore the Froude number is set to a constant value of 1 .

The unit response discharge, $q_{\mathrm{fd}}\left(\mathrm{m}^{2} \mathrm{~s}^{-1}\right)$, at the outlet of a drainage basin can be computed from Eqs. (3) to (5) by integrating the product of the cell response function $q_{\mathrm{d}}(x$, $t)$ corresponding to a delta-function input of the normalized area function, $A(x)$, i.e., the spatial distribution of rainfall input. The integral is given by

$q_{\mathrm{fd}}\left(t_{r}\right)=\int_{0}^{t_{p}} \frac{Q_{\mathrm{p}}}{w} \mathrm{~d} t^{\prime} \int^{L} 0 q_{\mathrm{d}}\left(x, t_{r}-t^{\prime}\right) A(x) \mathrm{d} x$,

where $t_{\mathrm{p}}$ is the time interval of measurement over which the unit impulse input (i.e., $Q_{\mathrm{p}}$ ) is applied to the idealized square drainage basin, and $t_{r}$ is the time after the input of the unit impulse that is long enough to capture the waxing and waning portions and the flood peak of the flood wave. The final peak discharge value, or $Q_{\mathrm{fd}}\left(\mathrm{m}^{3} \mathrm{~s}^{-1}\right)$, was calculated by multiplying the unit discharge $q_{\mathrm{fd}}\left(\mathrm{m}^{2} \mathrm{~s}^{-1}\right)$ by the channel width found through the formula derived from CRB data in Fig. 4 and then selecting the largest value from the resulting hydrograph.

\subsection{Estimation of uncertainty}

Confidence intervals (i.e., uncertainty estimates) were calculated to quantify the uncertainty in calculated rainfall intensities and associated $Q_{\mathrm{p}}$ and $Q_{\mathrm{fd}}$ values. In this study we estimated confidence intervals using a non-parametric method similar to that used to calculate quantiles for flowduration curves (Parzen, 1979; Vogel and Fennesset, 1994). Like quantile calculations, which identify a subset of the ranked data in the vicinity of each data point to estimate expected values and associated uncertainties, we estimated confidence intervals for our predictions based on the difference in $Q_{\mathrm{p}}$ values between each point and the next largest value in 
the ranked list. This approach quantifies the variation in the rainfall-intensity value for a given contributing area and recurrence interval. In some cases the calculated uncertainties for rainfall intensities and associated $Q_{\mathrm{p}}$ and $Q_{\mathrm{fd}}$ values are infinite due to the values being past the frequency-magnitude distribution; i.e., there are not enough samples for these values to be determined and there are no finite numbers to sample. These values are not used in this study.

The resulting confidence intervals of rainfall intensity were used to calculate confidence intervals for $Q_{\mathrm{p}}$ and $Q_{\mathrm{fd}}$. Confidence intervals for $Q_{\mathrm{p}}$ values were equal to the confidence intervals for rainfall intensity propagated through the calculation of $Q_{\mathrm{p}}$ (i.e., multiplying by contributing area). Confidence intervals for $Q_{\mathrm{fd}}$ values were calculated to be the same proportion of the $Q_{\mathrm{fd}}$ value as that set by the rainfall-intensity value and its confidence intervals. For example, if the upper confidence interval was $120 \%$ of a rainfall-intensity value, the upper confidence interval for the $Q_{\text {fd }}$ value associated with the rainfall-intensity value is assumed to be $120 \%$ of the $Q_{\text {fd }}$ value. This approach to propagation of uncertainty treats all other variables in the calculations as constants, and additional uncertainty related to regression analyses of variables used in the flow-routing algorithm such as slope, channel width, and runoff coefficients was not included.

\subsection{Testing the effects of climate variability}

To quantify the robustness of our results with respect to climate variability, we separated the NEXRAD data into El Niño and La Niña months using the multivariate ENSO index (MEI). All months of data with negative MEI values (La Niña conditions) were run together to calculate the rainfall intensity and $Q_{\mathrm{p}}$ values for contributing areas of 16, 256, and $4096 \mathrm{~km}^{2}$, time intervals of 1 to $64 \mathrm{~h}$, and for 10-, 50-, 100-, and 500-year recurrence intervals. This was repeated with all months of data with positive MEI values (El Niño conditions). Figure 5 shows the distribution of negative and positive MEI values during the 1996 to 2004 water years used in this study.

\section{Results}

\subsection{Channel characteristics and runoff coefficients}

Least-squares regression of channel slopes and channel widths from the CRB vs. contributing area was used to estimate channel slope, channel width, and runoff coefficients for each idealized basin of a specific contributing-area class. Channel slope decreases as a power-law function of contributing area with an exponent of $-0.30\left(R^{2}=0.39\right)$, whereas channel width increases as a power-law function of contributing area with an exponent of $0.28\left(R^{2}=0.65\right.$; Fig. 4). These results follow the expected relationships among channel slopes, widths, and contributing area; i.e., as

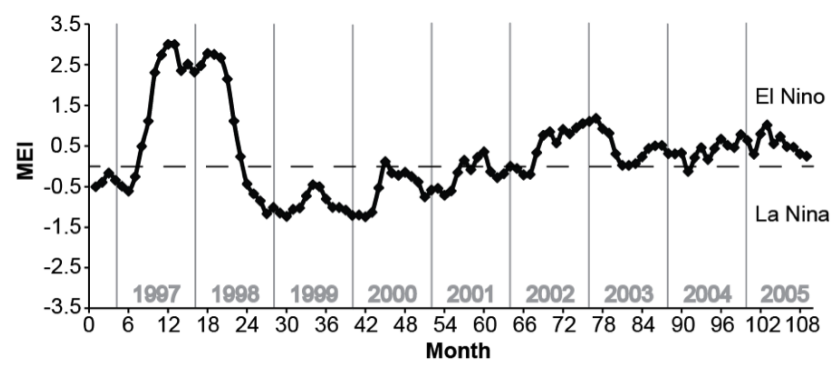

Figure 5. Multivariate ENSO index (MEI) of months included in Stage III NEXRAD gridded products. Months are numbered from September 1996 to September 2005 with years shown in gray. Dashed black line MEI equal to zero. A positive MEI indicates El Niño conditions, while a negative MEI indicates La Niña conditions.

contributing area increases, the channel slope decreases and the channel width increases.

Runoff coefficients for wet, medium, and dry antecedentmoisture conditions all decrease with increasing contributing area following a logarithmic function, with the slope of the line decreasing from wet to dry conditions. The fitness of the line to the data also decreases for the wet to dry conditions, with the $R^{2}$ values for wet, medium, and dry conditions equal to $0.78,0.45$, and 0.04 , respectively. Runoff coefficients decrease with increasing contributing area due to the increased probability of water losses as basin area increases. Also, as expected, runoff coefficients are highest in basins with wet initial conditions that are primed to limit infiltration and evapotranspiration.

\subsection{Trends in rainfall intensity}

Maximum rainfall intensities (i.e., the maximum among all time-interval-of-measurement classes) for each contributingarea class and recurrence interval decrease systematically as power-law functions of increasing contributing area for all recurrence intervals with an average exponent of $-0.18 \pm 0.06$ (error is the standard deviation of all calculated exponents found from a weighted least-squares regression; average coefficient of determination $R^{2}=0.78$ ). Note that maximum-rainfall-intensity results are not presented because they are closely related to the plots of $Q_{\mathrm{p}}$ vs. contributing area in Fig. 6; i.e., $Q_{\mathrm{p}}$ is simply the rainfall intensity multiplied by the contributing area. The decrease in maximum rainfall intensity with contributing area can be seen in Table 1, where maximum rainfall intensities over contributing areas of $11664 \mathrm{~km}^{2}$ are 45 to $8 \%$ of maximumrainfall-intensity values for basin areas of $16 \mathrm{~km}^{2}$ in both the UCRB and LCRB (Table 1). The largest decrease in maximum-rainfall-intensity values between the smallest and largest contributing areas were found for the largest recurrence interval (e.g., 500-year) for both the UCRB and LCRB. The decrease in maximum rainfall intensity with increasing 

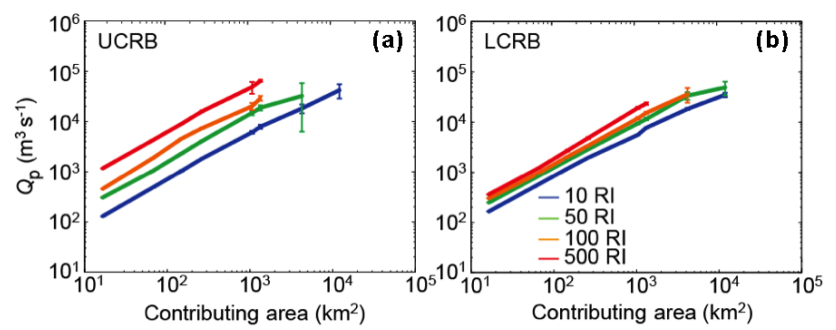

Figure 6. Frequency-magnitude-area (FMA) curves of $Q_{\mathrm{p}}$ vs. contributing area for recurrence intervals (RIs) of 10, 50, 100, and 500 years for the Upper Colorado River Basin (UCRB; a) and the Lower Colorado River Basin (LCRB; b).

contributing area suggests that there is a spatial limitation to storms of a given rainfall intensity.

Differences among maximum rainfall intensities for the four recurrence intervals as a function of contributing area are larger in the UCRB than in the LCRB (Table 1). This larger "spread" in the maximum rainfall intensities in the UCRB relative to the LCRB is also propagated throughout the maximum rainfall and flood discharge calculations. For both the UCRB and LCRB, the difference between the 50and 100-year recurrence-interval values was the smallest (Table 1). These trends show that maximum rainfall intensities vary much more as a function of recurrence interval in the UCRB compared with the LCRB.

Maximum rainfall intensities associated with a 10 -year recurrence interval are similar in the LCRB and UCRB, while intensities were higher in the UCRB than the LCRB for recurrence intervals of 50, 100, and 500 years (Table 1). The results of the comparison between the two basins suggest that common (i.e., low-recurrence-interval) rainfall events will have similar maximum rainfall intensities in the UCRB and LCRB, but that rare (i.e., high-recurrence-interval) rainfall events will have higher maximum rainfall intensities in the UCRB than in the LCRB for the same recurrence interval.

Maximum precipitation intensities associated with the four defined recurrence intervals are similar to previously published values. In general the values we calculate for the LCRB and the UCRB for the 10-, 50-, and 100-year recurrence intervals are on the order of $10 \mathrm{~s}$ of $\mathrm{mm} \mathrm{h}^{-1}$. This is similar to the spread in values reported on precipitation intensity maps for the same duration and recurrence interval in Hershfield (1961). However, the values reported by Hershfield (1961) are slightly higher (by less than $20 \mathrm{~mm} \mathrm{~h}^{-1}$ ) in the LCRB for the three recurrence intervals and in the UCRB for the 10-year recurrence interval than values calculated in this study. The values calculated here are also broadly consistent with presented precipitation frequency estimates for points within the LCRB and UCRB provided by the NOAA Atlas 14 Point Precipitation Frequency Estimates website (http://hdsc.nws.noaa. gov/hdsc/pfds/pfds_map_cont.html). Due to the difference in how precipitation intensities are measured and how the frequencies are calculated, the values are expected to be slightly different but within the same order of magnitude.

\subsection{Trends in $Q_{\mathrm{p}}$}

Maximum precipitation (here only rainfall) discharges $\left(Q_{\mathrm{p}}\right.$ hereafter) increase with contributing area as power-law functions with an average exponent of $0.82 \pm 0.06$ (error is the standard deviation of all calculated exponents) based on weighed least-squares regressions on the data $\left(R^{2}=0.98\right)$ for all recurrence intervals and for both the UCRB and LCRB (Fig. 6). These $Q_{\mathrm{p}}$ values for a given contributing-area class and recurrence interval are the largest values taken from the multiple values calculated for each of the seven time intervals of measurement as explained in Sect. 3.3. By taking the maximum values, the resulting $Q_{\mathrm{p}}$ FMACs approximate the upper envelope of values of a given recurrence interval. In this study the FMAC follows a power-law function that shows that $Q_{\mathrm{p}}$ increases predictably across the range in contributing areas. As with the maximum rainfall-intensity results, differences between $Q_{\mathrm{p}}$ values of different recurrence intervals for a given contributing area were larger for the UCRB than the LCRB (Fig. 6).

In general, confidence intervals for $Q_{\mathrm{p}}$ values increase with increasing contributing-area class (Table 1 and Fig. 6). The large values of the highest contributing-area classes and highest recurrence intervals show the spatial limitation of the method, meaning that at these contributing-area classes and recurrence intervals the values are sampled from the largest ranked value and have infinite confidence intervals. These values include the 50-, 100-, and 500-year recurrence intervals for the UCRB and the 100- and 500-year recurrence intervals for the LCRB at the $11664 \mathrm{~km}^{2}$ contributing-area class. These values also include the 100- and 500-year recurrence intervals for the UCRB and the 500-year recurrence intervals for the LCRB at the $4096 \mathrm{~km}^{2}$ contributing-area class. Values with infinite confidence intervals are not included in Fig. 6 due to their high uncertainties.

\subsection{Trends in $Q_{\mathrm{fd}}$}

Maximum $Q_{\mathrm{fd}}$ values (hereafter $Q_{\mathrm{fd}}$ ), i.e., the largest values taken for the multiple values calculated for each time interval of measurement for a given contributing-area class and recurrence interval, were used to plot FMACs for wet, medium, and dry conditions for both the UCRB and LCRB (Fig. 7). In general, FMACs for $Q_{\mathrm{fd}}$ values follow the power-law relationship shown in the $Q_{\mathrm{p}}$ FMACs until contributing areas of $\sim 1000 \mathrm{~km}^{2}$, where the curves begin to very slightly flatten or decrease. As with the $Q_{\mathrm{p}}$ values, $Q_{\mathrm{fd}}$ values representing some of the higher recurrence intervals converge to the same value (i.e., the value corresponding to the highest rainfall intensity for the contributing-area class) at contributing areas of $\approx 10000 \mathrm{~km}^{2}$ and the confidence intervals become infi- 
Table 1. Maximum rainfall intensity and $Q_{\mathrm{p}}$ for the Upper Colorado River Basin (UCRB) and Lower Colorado River Basin (LCRB). Note that data are all sampled from time intervals of measurement $\leq 2 \mathrm{~h}$.

\begin{tabular}{|c|c|c|c|c|c|}
\hline \multirow[t]{2}{*}{ RI } & \multirow{2}{*}{$\begin{array}{l}\text { Area } \\
\left(\mathrm{km}^{2}\right)\end{array}$} & \multicolumn{2}{|c|}{ Intensity $\left(\mathrm{mm} \mathrm{h}^{-1}\right)$} & \multicolumn{2}{|c|}{$Q_{\mathrm{p}}\left(\mathrm{m}^{3} \mathrm{~s}^{-1}\right)$} \\
\hline & & UCRB & LCRB & UCRB & LCRB \\
\hline 10 & 16 & $28.0 \pm 0.0$ & $36.6 \pm 0.0$ & $125 \pm 0$ & $162 \pm 0$ \\
\hline 10 & 64 & $25.4 \pm 0.1$ & $32.5 \pm 0.0$ & $451 \pm 1$ & $578 \pm 0$ \\
\hline 10 & 144 & $25.1 \pm 1.1$ & $29.5 \pm 0.4$ & $1004 \pm 44$ & $1182 \pm 16$ \\
\hline 10 & 256 & $23.7 \pm 0.2$ & $27.3 \pm 0.0$ & $1682 \pm 13$ & $1944 \pm 1$ \\
\hline 10 & 1024 & $19.8 \pm 1.5$ & $19.7 \pm 0.4$ & $5644 \pm 427$ & $5610 \pm 114$ \\
\hline 10 & 1296 & $20.7 \pm 2.4$ & $21.7 \pm 3.5$ & $7439 \pm 873$ & $7820 \pm 1268$ \\
\hline 10 & 4096 & $15.5 \pm 3.0$ & $15.9 \pm 0.8$ & $17682 \pm 3462$ & $18134 \pm 890$ \\
\hline 10 & 11664 & $12.6 \pm 1.7$ & $11.0 \pm 2.6$ & $40914 \pm 5571$ & $35521 \pm 8586$ \\
\hline 50 & 16 & $55.9 \pm 0.7$ & $56.2 \pm 0.1$ & $248 \pm 3$ & $250 \pm 0$ \\
\hline 50 & 64 & $55.1 \pm 1.2$ & $47.7 \pm 0.0$ & $980 \pm 22$ & $847 \pm 1$ \\
\hline 50 & 144 & $55.3 \pm 3.5$ & $43.3 \pm 0.9$ & $2211 \pm 142$ & $1734 \pm 38$ \\
\hline 50 & 256 & $54.9 \pm 1.4$ & $40.9 \pm 0.5$ & $3901 \pm 101$ & $2908 \pm 32$ \\
\hline 50 & 1024 & $50.8 \pm 5.5$ & $33.6 \pm 1.4$ & $14449 \pm 1569$ & $9560 \pm 393$ \\
\hline 50 & 1296 & $50.8 \pm 25.0$ & $32.5 \pm 3.9$ & $18287 \pm 9011$ & $11704 \pm 1410$ \\
\hline 50 & 4096 & $27.6 \pm 22.2$ & $30.0 \pm 5.2$ & $31382 \pm 25313$ & $34126 \pm 5969$ \\
\hline 50 & 11664 & $21.1^{*}$ & $15.4 \pm 8.3$ & $68434^{*}$ & $49764 \pm 26874$ \\
\hline 100 & 16 & $92.3 \pm 0.3$ & $68.6 \pm 0.0$ & $410 \pm 1$ & $305 \pm 0$ \\
\hline 100 & 64 & $91.9 \pm 2.5$ & $54.5 \pm 0.2$ & $1635 \pm 44$ & $970 \pm 3$ \\
\hline 100 & 144 & $90.1 \pm 3.0$ & $51.9 \pm 1.0$ & $3606 \pm 118$ & $2075 \pm 41$ \\
\hline 100 & 256 & $88.7 \pm 4.3$ & $48.4 \pm 0.4$ & $6305 \pm 307$ & $3440 \pm 27$ \\
\hline 100 & 1024 & $63.8 \pm 11.0$ & $42.5 \pm 2.2$ & $18155 \pm 3139$ & $12085 \pm 630$ \\
\hline 100 & 1296 & $78.5 \pm 50.1$ & $43.2 \pm 7.8$ & $28257 \pm 18022$ & $15544 \pm 2820$ \\
\hline 100 & 4096 & $40.8^{*}$ & $32.0 \pm 10.4$ & $46422 *$ & $36425 \pm 11803$ \\
\hline 100 & 11664 & $21.1^{*}$ & $20.1^{*}$ & $68434^{*}$ & $65011^{*}$ \\
\hline 500 & 16 & $254.0 \pm 0.8$ & $81.9 \pm 0.5$ & $1129 \pm 3$ & $364 \pm 2$ \\
\hline 500 & 64 & $229.0 \pm 3.1$ & $68.6 \pm 1.5$ & $4071 \pm 55$ & $1219 \pm 26$ \\
\hline 500 & 144 & $219.1 \pm 11.9$ & $68.6 \pm 4.7$ & $8762 \pm 476$ & $2743 \pm 187$ \\
\hline 500 & 256 & $219.4 \pm 7.3$ & $68.6 \pm 3.4$ & $15600 \pm 517$ & $4877 \pm 242$ \\
\hline 500 & 1024 & $166.0 \pm 44.1$ & $68.6 \pm 3.1$ & $47229 \pm 12554$ & $19507 \pm 884$ \\
\hline 500 & 1296 & $174.6 \pm 85.3$ & $65.6 \pm 31.3$ & $62862 \pm 30696$ & $23624 \pm 11279$ \\
\hline 500 & 4096 & $81.6^{*}$ & $53.6^{*}$ & $92844^{*}$ & $60930^{*}$ \\
\hline 500 & 11664 & $21.1^{*}$ & $20.1^{*}$ & $68434^{*}$ & $65011^{*}$ \\
\hline
\end{tabular}

* Values with infinite confidence intervals; not used in this study.

nite (Table 2). This convergence of $Q_{\mathrm{fd}}$ values at the largest contributing areas is due to the reduction in the range of values and the number of samples from which to calculate the associated values for each recurrence interval.

In general, the UCRB $Q_{\mathrm{fd}}$ FMACs (Fig. 7a, c, and e) are slightly higher in magnitude and span a larger range of magnitudes than the FMACs for the LCRB. For both basins, FMACs for the wet, medium, and dry conditions resulted in the highest, middle, and lowest magnitudes, respectively. This trend is expected due to the lowering of runoff coefficients and available water as conditions become drier.

FMACs of $Q_{\mathrm{fd}}$ for the LCRB plot below published FECs for the LCRB and US (Fig. 7b, d, and f) at low contributing areas, but meet and/or exceed the LCRB FEC for con- tributing areas above $\approx 1000$ and $\approx 100 \mathrm{~km}^{2}$ for dry and wet antecedent-moisture conditions, respectively. The FMACs for the LCRB do not exceed the US FEC. All of the FMACs of $Q_{\mathrm{fd}}$ for the UCRB exceed the LCRB FEC for wet conditions, with the FMACs of lower recurrence intervals exceeding the curve at higher contributing areas than the FMACs of higher recurrence intervals (Fig. 7a). The 500-year FMAC for wet conditions approximates the US FEC for contributing areas between $\approx 100$ and $1000 \mathrm{~km}^{2}$. These results suggest that under certain antecedent-moisture conditions, and in basins of certain contributing areas, the LCRB produces floods that exceed the maximum recorded floods in the LCRB, and the UCRB produces floods of magnitudes on par with the maximum recorded floods in the US. 
Table 2. Maximum $Q_{\mathrm{fd}}$ for the Upper Colorado River Basin (UCRB) and Lower Colorado River Basin (LCRB). Note that data are all sampled from time intervals of measurement $\leq 2 \mathrm{~h}$.

\begin{tabular}{|c|c|c|c|c|c|c|c|}
\hline \multirow[t]{2}{*}{ RI } & \multirow{2}{*}{$\begin{array}{l}\text { Area } \\
\left(\mathrm{km}^{2}\right)\end{array}$} & \multicolumn{2}{|c|}{ Wet $Q_{\mathrm{fd}}\left(\mathrm{m}^{3} \mathrm{~s}^{-1}\right)$} & \multicolumn{2}{|c|}{$\operatorname{Med} Q_{\mathrm{fd}}\left(\mathrm{m}^{3} \mathrm{~s}^{-1}\right)$} & \multicolumn{2}{|c|}{ Dry $Q_{\mathrm{fd}}\left(\mathrm{m}^{3} \mathrm{~s}^{-1}\right)$} \\
\hline & & UCRB & LCRB & UCRB & LCRB & UCRB & LCRB \\
\hline 10 & 16 & $65 \pm 0$ & $86 \pm 0$ & $36 \pm 0$ & $47 \pm 0$ & $20 \pm 0$ & $26 \pm 0$ \\
\hline 10 & 64 & $246 \pm 1$ & $263 \pm 0$ & $137 \pm 0$ & $151 \pm 0$ & $75 \pm 0$ & $89 \pm 0$ \\
\hline 10 & 144 & $465 \pm 20$ & $489 \pm 7$ & $268 \pm 12$ & $290 \pm 4$ & $156 \pm 7$ & $175 \pm 2$ \\
\hline 10 & 256 & $657 \pm 5$ & $748 \pm 0$ & $388 \pm 3$ & $449 \pm 0$ & $244 \pm 2$ & $283 \pm 0$ \\
\hline 10 & 1024 & $2363 \pm 179$ & $2194 \pm 44$ & $1423 \pm 108$ & $1326 \pm 27$ & $892 \pm 68$ & $820 \pm 17$ \\
\hline 10 & 1296 & $2244 \pm 263$ & $2384 \pm 387$ & $1459 \pm 171$ & $1543 \pm 250$ & $1010 \pm 118$ & $1066 \pm 173$ \\
\hline 10 & 4096 & $5594 \pm 1095$ & $5304 \pm 260$ & $3665 \pm 718$ & $3375 \pm 166$ & $2507 \pm 491$ & $2315 \pm 114$ \\
\hline 10 & 11664 & $14603 \pm 1966$ & $11048 \pm 2670$ & $9010 \pm 1213$ & $6978 \pm 1687$ & $6105 \pm 822$ & $4942 \pm 1195$ \\
\hline 50 & 16 & $131 \pm 2$ & $131 \pm 0$ & $73 \pm 1$ & $73 \pm 0$ & $41 \pm 1$ & $41 \pm 0$ \\
\hline 50 & 64 & $553 \pm 12$ & $387 \pm 0$ & $307 \pm 7$ & $222 \pm 0$ & $172 \pm 4$ & $130 \pm 0$ \\
\hline 50 & 144 & $1145 \pm 73$ & $720 \pm 16$ & $636 \pm 41$ & $424 \pm 9$ & $355 \pm 23$ & $259 \pm 6$ \\
\hline 50 & 256 & $1772 \pm 46$ & $1119 \pm 12$ & $1043 \pm 27$ & $676 \pm 7$ & $639 \pm 16$ & $421 \pm 5$ \\
\hline 50 & 1024 & $6127 \pm 665$ & $3062 \pm 126$ & $3665 \pm 398$ & $1928 \pm 79$ & $2291 \pm 249$ & $1308 \pm 54$ \\
\hline 50 & 1296 & $7076 \pm 3487$ & $3562 \pm 429$ & $4265 \pm 2102$ & $2300 \pm 277$ & $2682 \pm 1321$ & $1571 \pm 189$ \\
\hline 50 & 4096 & $15716 \pm 12650$ & $8487 \pm 1485$ & $9451 \pm 7607$ & $5850 \pm 1023$ & $6076 \pm 4890$ & $4343 \pm 760$ \\
\hline 50 & 11664 & $44482^{*}$ & $15700 \pm 8478$ & $28783^{*}$ & $10176 \pm 5495$ & $19770^{*}$ & $7138 \pm 3855$ \\
\hline 100 & 16 & $216 \pm 1$ & $160 \pm 0$ & $120 \pm 0$ & $89 \pm 0$ & $67 \pm 0$ & $50 \pm 0$ \\
\hline 100 & 64 & $924 \pm 25$ & $442 \pm 1$ & $514 \pm 14$ & $255 \pm 1$ & $286 \pm 8$ & $150 \pm 0$ \\
\hline 100 & 144 & $1807 \pm 60$ & $860 \pm 17$ & $1041 \pm 35$ & $508 \pm 10$ & $610 \pm 20$ & $309 \pm 6$ \\
\hline 100 & 256 & $2888 \pm 140$ & $1324 \pm 10$ & $1706 \pm 83$ & $798 \pm 6$ & $1037 \pm 50$ & $499 \pm 4$ \\
\hline 100 & 1024 & $10586 \pm 1830$ & $3812 \pm 199$ & $6366 \pm 1101$ & $2438 \pm 127$ & $3979 \pm 688$ & $1662 \pm 87$ \\
\hline 100 & 1296 & $9564 \pm 6100$ & $4713 \pm 855$ & $5752 \pm 3668$ & $3058 \pm 555$ & $3619 \pm 2308$ & $2104 \pm 382$ \\
\hline 100 & 4096 & $29415^{*}$ & $10319 \pm 3344$ & $19095^{*}$ & $6654 \pm 2156$ & $13116^{*}$ & $4698 \pm 1522$ \\
\hline 100 & 11664 & $59600^{*}$ & $18607^{*}$ & $38667^{*}$ & $12904^{*}$ & $26747^{*}$ & $9609^{*}$ \\
\hline 500 & 16 & $594 \pm 2$ & $192 \pm 1$ & $330 \pm 1$ & $107 \pm 1$ & $184 \pm 1$ & $59 \pm 0$ \\
\hline 500 & 64 & $1855 \pm 25$ & $556 \pm 12$ & $1068 \pm 14$ & $320 \pm 7$ & $628 \pm 8$ & $188 \pm 4$ \\
\hline 500 & 144 & $3631 \pm 197$ & $1138 \pm 77$ & $2141 \pm 116$ & $670 \pm 46$ & $1306 \pm 71$ & $408 \pm 28$ \\
\hline 500 & 256 & $6012 \pm 200$ & $1879 \pm 93$ & $3618 \pm 120$ & $1130 \pm 56$ & $2266 \pm 75$ & $709 \pm 35$ \\
\hline 500 & 1024 & $19049 \pm 5059$ & $6139 \pm 278$ & $11478 \pm 3048$ & $3945 \pm 179$ & $7186 \pm 1909$ & $2660 \pm 120$ \\
\hline 500 & 1296 & $19075 \pm 9314$ & $7153 \pm 3415$ & $12370 \pm 6041$ & $4656 \pm 2223$ & $8499 \pm 4150$ & $3198 \pm 1527$ \\
\hline 500 & 4096 & $43688^{*}$ & $14892^{*}$ & $28354^{*}$ & $10460^{*}$ & $19481^{*}$ & $7800^{*}$ \\
\hline 500 & 11664 & $65705^{*}$ & $23062^{*}$ & $42738^{*}$ & $16198^{*}$ & $29364^{*}$ & $12080^{*}$ \\
\hline
\end{tabular}

* Values with infinite confidence intervals; not used in this study.

\subsection{The effects of ENSO on rainfall}

Definitive differences in maximum rainfall intensities and $Q_{\mathrm{p}}$ values were found between months with positive vs. months with negative MEI values (Table 3). For very small contributing areas $\left(16 \mathrm{~km}^{2}\right)$ in the LCRB, maximum rainfall intensities and $Q_{\mathrm{p}}$ values are similar during negative and positive MEI conditions. Larger contributing areas (256 and $4096 \mathrm{~km}^{2}$ ) show higher maximum rainfall intensities during negative MEI conditions regardless of recurrence interval. Values of $Q_{\mathrm{p}}$ show the same trend as the maximum rainfall intensity in the LCRB. In the UCRB, maximum rainfall intensities and $Q_{\mathrm{p}}$ values during negative MEI conditions are higher than those during positive MEI conditions regardless of recurrence interval.

\section{Discussion}

\subsection{Use and accuracy of NEXRAD products}

NEXRAD products are widely used as precipitation inputs in rainfall-runoff modeling studies due to the spatially complete nature of the data necessary for hydrologic and atmospheric models (Ogden and Julien, 1994; Giannoni et al., 2003; Kang and Merwade, 2011). In contrast to past studies similar in scope to this study (Castellarin et al., 2005, 2009; Castellarin, 2007), we did not use rain-gauge data and only 
Table 3. Maximum rainfall intensity and $Q_{\mathrm{p}}$ values for 10-, 50-, 100-, and 500-year recurrence intervals during negative (neg) and positive (pos) multivariate ENSO index (MEI) conditions within the Lower Colorado River Basin (LCRB) and Upper Colorado River Basin (UCRB). Note that data are all sampled from time intervals of measurement $\leq 2 \mathrm{~h}$.

\begin{tabular}{|c|c|c|c|c|c|c|c|c|c|c|}
\hline \multirow[t]{2}{*}{ Basin } & \multirow[t]{2}{*}{ MEI } & \multirow{2}{*}{$\begin{array}{l}\text { Area } \\
\left(\mathrm{km}^{2}\right)\end{array}$} & \multicolumn{4}{|c|}{ Intensity $\left(\mathrm{mm} \mathrm{h}^{-1}\right)$} & \multicolumn{4}{|c|}{$Q_{\mathrm{p}}\left(\mathrm{m}^{3} \mathrm{~s}^{-1}\right)$} \\
\hline & & & $10 \mathrm{yr}$ & $50 \mathrm{yr}$ & $100 \mathrm{yr}$ & $500 \mathrm{yr}$ & $10 \mathrm{yr}$ & $50 \mathrm{yr}$ & $100 \mathrm{yr}$ & $500 \mathrm{yr}$ \\
\hline \multirow{6}{*}{ LCRB } & neg & 16 & 39 & 56 & 69 & 77 & 175 & 250 & 305 & 343 \\
\hline & neg & 256 & 31 & 46 & 53 & 69 & 2206 & 3251 & 3741 & 4877 \\
\hline & neg & 4096 & 21 & 32 & 43 & 54 & 23856 & 36425 & 48363 & 60930 \\
\hline & pos & 16 & 40 & 64 & 74 & 130 & 179 & 284 & 330 & 576 \\
\hline & pos & 256 & 27 & 38 & 47 & 52 & 1943 & 2690 & 3369 & 3721 \\
\hline & pos & 4096 & 13 & $20^{*}$ & $20^{*}$ & $20^{*}$ & 15229 & $22689^{*}$ & $22689^{*}$ & $22689^{*}$ \\
\hline \multirow[t]{6}{*}{ UCRB } & neg & 16 & 41 & 98 & 162 & 254 & 186 & 435 & 721 & 1129 \\
\hline & neg & 256 & 33 & 101 & 155 & 254 & 2366 & 7172 & 11012 & 18055 \\
\hline & neg & 4096 & 22 & 34 & 41 & 82 & 25556 & 39013 & 46422 & 92844 \\
\hline & pos & 16 & 26 & 51 & 56 & 74 & 115 & 225 & 248 & 330 \\
\hline & pos & 256 & 18 & 40 & 51 & 56 & 1255 & 2810 & 3601 & 4018 \\
\hline & pos & 4096 & 10 & 26 & $27^{*}$ & $27^{*}$ & 10822 & 30034 & $31044^{*}$ & $31044^{*}$ \\
\hline
\end{tabular}

* Values with infinite confidence intervals; not used in this study.
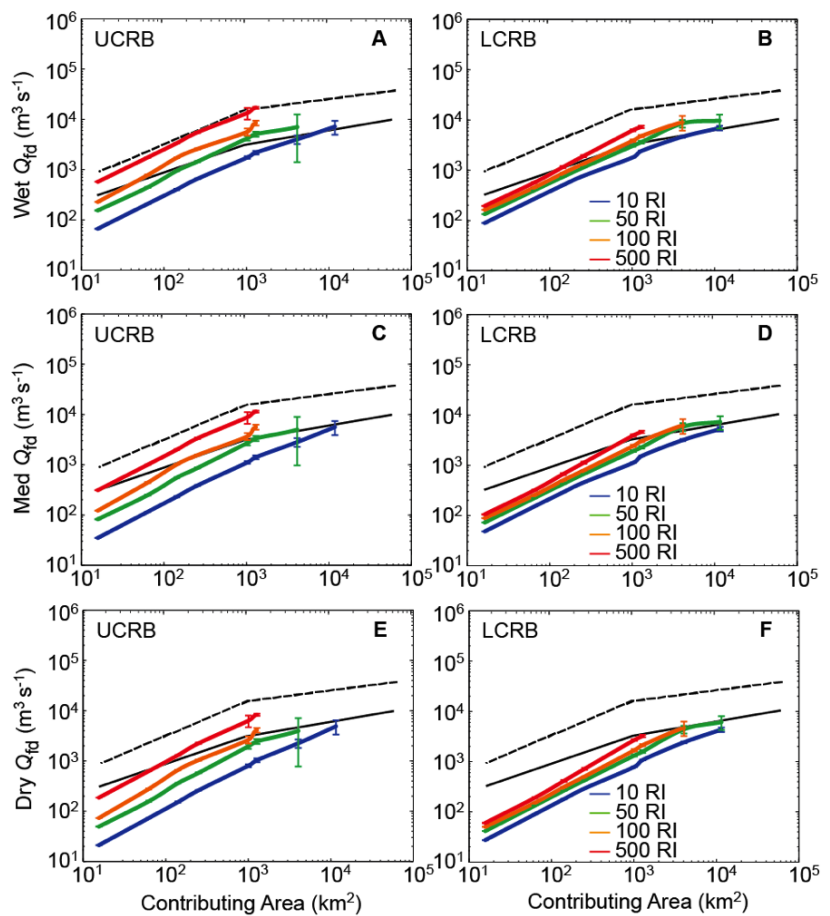

Figure 7. $Q_{\mathrm{fd}}$ frequency-magnitude-area curves of $10,50,100$, and 500-year recurrence intervals (RIs) and for wet, medium, and dry conditions for the Upper Colorado River Basin (UCRB) and the Lower Colorado River Basin (LCRB). Published FECs (black lines) for the Lower Colorado River Basin (solid black line) from Enzel et al. (1993) and the US (dashed black line) from Costa (1987) are also shown. used NEXRAD products to determine the FMACs for precipitation and flood discharges. We favor NEXRAD products due to the spatial completeness of the data.

Intuitively, NEXRAD products that are spatially complete and average precipitation over a $4 \mathrm{~km}$ by $4 \mathrm{~km}$ area would not be expected to match rain-gauge data within that area precisely (due to the multi-scale variability of rainfall), although some studies have tried to address this discrepancy (Sivapalan and Bloschl, 1998; Johnson et al., 1999). Xie et al. (2006) studied a semi-arid region in central New Mexico and found that hourly NEXRAD products overestimated the mean precipitation relative to rain-gauge data in both monsoon and non-monsoon seasons by upwards of 33 and $55 \%$, respectively. Overestimation of precipitation has also been noted due to the range and the tilt angle at which radar reflectivity data are collected (Smith et al., 1996). Underestimation of precipitation by NEXRAD products relative to rain-gauge data has also been observed (Smith et al., 1996; Johnson et al., 1999), however.

Under- and over-estimation of precipitation by NEXRAD products in relation to rain-gauge data is partly due to the difference in sampling between areal NEXRAD products and point data from rain gauges and partly due to sampling errors inherent to both methods. For example, NEXRAD products include problems such as the use of incorrect $Z-R$ relationships for high-intensity storms and different types of precipitation, such as snow and hail (Baeck and Smith, 1998). Also, because of its low reflectivity, snow in the NEXRAD products is measured as if it were light rain (David Kitzmiller, personal communication, 10 January 2012). This means the NEXRAD products likely underestimate snowfall and therefore snowfall is not fully accounted for in this study. Due to 
snowfall not being included in this study, associated snowpack and snowmelt effects were also not accounted for. Rain gauges can also suffer from a number of measurement errors that usually result in an underestimation of rainfall (Burton Jr. and Pitt, 2001). In addition, gridded rainfall data derived from rain gauges are not spatially complete and therefore must be interpolated between point measurements to form a spatially complete model of rainfall. It is impossible to discern which product is more correct due to the differences in measurement techniques and errors, but by taking both products and combining them into one, the Stage III NEXRAD precipitation products generate the best precipitation estimate possible for this study. Moreover, it should be noted that 100-year flood magnitude predictions based on regression equations have very large relative error bars (ranging between 37 and $120 \%$ in the western US; Parrett and Johnson, 2003) and that measurements of past extreme floods can have significant errors ranging from 25 to $130 \%$, depending on the method used (Baker, 1987). As such, even a $\sim 50 \%$ bias in NEXRAD-product-derived precipitation estimates is on par or smaller than the uncertainty associated with an analysis of extreme flood events.

As stated previously, the NEXRAD precipitation estimates used here do not include snowfall and other non-rainfall precipitation types. In this study we also do not include snowpack information in our flood discharge calculations. The omission of snowpack is a reasonable assumption for our low-elevation, warm regions within most of the UCRB and LCRB. However, we acknowledge that some of our higher elevation areas at higher latitudes may underestimate the maximum flood discharge by only including rainfall-derived runoff. If the methodology in this paper were applied to a snowmelt-dominated region, snowpack would need to be added to accurately estimate the maximum flood discharge.

\subsection{Comparison of FMACs to published FECs}

FMACs of $Q_{\mathrm{fd}}$ exhibit a similar shape and similar overall range in magnitudes to previously published FECs, derived from stream-gauge and paleoflood records, for the LCRB and the US (Fig. 7). In general, the FMACs exceed or match published FECs at larger contributing areas, and are lower than or on par with published FECs at the smallest contributing areas (Fig. 7).

All FMACs except the 500-year recurrence-interval curve for the UCRB under wet conditions are positioned well below the US FEC presented by Costa (1987; Fig. 7a). The similarity between the 500-year recurrence interval $Q_{\mathrm{fd}}$ FMAC for the UCRB under wet conditions and the US FEC suggests that the US FEC includes floods of larger recurrenceintervals, which are similar in magnitude to the 500-year recurrence-interval floods within the UCRB. The approximation of the US FEC by the 500-year UCRB FMAC is a significant finding due to the fact that the US FEC includes storms from other regions of the US with extreme climatic forcings (i.e., hurricanes, extreme convection storms).

The $Q_{\mathrm{fd}}$ FMACs for the LCRB can be directly compared to the FEC for the LCRB presented by Enzel et al. (1993). At contributing areas smaller than approximately $100 \mathrm{~km}^{2}, Q_{\mathrm{fd}}$ FMACs for wet conditions and all recurrence intervals are positioned below the LCRB FEC, but at larger contributing areas $Q_{\mathrm{fd}}$ FMACs exceed or approximate the LCRB FEC. $Q_{\mathrm{fd}}$ FMACs calculated for medium and dry antecedent conditions show the same trend, but exceed the LCRB FEC at larger contributing areas $\left(\geq 1000 \mathrm{~km}^{2}\right)$. This comparison suggests that although the FMACs overlap the overall range of flood magnitudes of the LCRB FEC, the two methods are not capturing the same trend for extreme flood discharges and the LCRB is capable of producing floods larger than those on record.

The difference in the slope of the FMACs, and specifically the exceedance of the published LCRB FEC, suggests that the two methods are not capturing the same information. This difference may be due to the difference in how the data are sourced for each method. FECs are created as regional estimates of maximum flood discharges and are based on stream-gauging station and paleoflood data. The FECs are then used to provide flood information for the region, including ungauged and unstudied drainage basins. FECs are limited to the number of stream gauges employed by public and private parties and do not include all basins within a region. In general, FECs may underestimate maximum floods in larger basins, relative to smaller basins, because there are a larger number of smaller basins to sample than larger basins. This sample-size problem introduces bias in the record where flood estimates for smaller contributing areas may be more correct than estimates for larger basins. In this study, the regional precipitation information given by the NEXRAD network is used to form the FMAC, therefore taking advantage of the entire region and using precipitation data to calculate flood discharges, rather than directly measuring flood discharges. This sampling scheme allows for much larger sample sizes for the range of contributing areas, therefore minimizing the sample bias of the traditional FEC.

This study aimed to introduce the new method of the FMAC and therefore improve upon the traditional methods of the FEC. By calculating FMACs we provide frequency and magnitude information of possible flood events for a given region, in contrast to the FECs that only provide an estimate of the largest flood on record. This information is vital for planning and infrastructure decisions and the accurate representation of precipitation and flooding in designstorm and watershed modeling. In addition, the fact that the FMACs match the FECs for large (500-year) recurrence intervals and do not exhibit the same trends suggests that the FMACs are capturing different samples than the FECs. This indicates that by using the NEXRAD products, the FMACs may provide a more inclusive flood dataset for a region (es- 


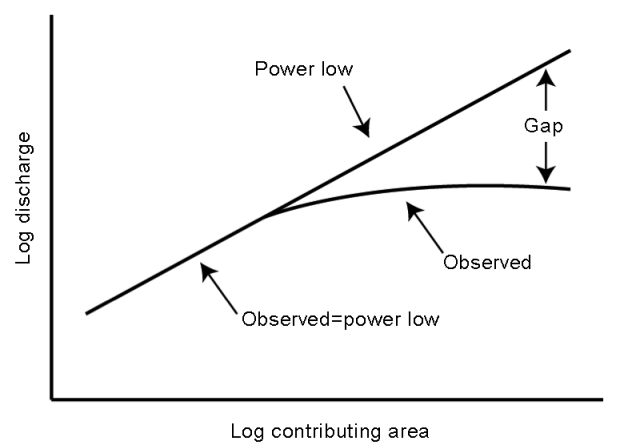

Figure 8. Conceptual diagram of the characteristic concave-down shape of the FEC (observed) shown in comparison to a power-law function between $Q_{\mathrm{p}}$ and contributing area. The "gap" between the observed curve and the predicted power law is caused by precipitation limitations and mechanisms occurring during the routing of water over the landscape.

pecially ungauged areas) than the traditional stream-gauge records.

\subsection{Precipitation controls on the form of the FEC}

$Q_{\mathrm{p}}$ FMACs were shown to have a strong (average $R^{2}=0.93$ ) power-law relationship between $Q_{\mathrm{p}}$ and contributing area for all recurrence intervals. Figure 8 shows a conceptualized FEC where the concave-down shape is created when the observed envelope curve diverges from the constant positive power-law relationship between $Q_{\mathrm{p}}$ and contributing area. This diversion creates a "gap" between the two curves and indicates that flood discharge is not a simple power-law function of contributing area. Three mechanisms have been proposed to explain the "gap" and characteristic concave-down shape of FECs: (1) integrated precipitation (i.e., total precipitation over an area) is more limited over larger contributing areas compared to smaller contributing areas (Costa, 1987), (2) a relative decrease in maximum flood discharges in larger contributing areas due to geomorphic dispersion (RodriguezIturbe and Valdes, 1979; Rinaldo et al., 1991; Saco and Kumar, 2004), and (3) a relative decrease in maximum flood discharges in larger basins due to hydrodynamic dispersion (Rinaldo et al., 1991). The first explanation, proposed by Costa (1987), suggests that there is a limitation to the size of a storm and the amount of water that a storm can precipitate. The effect of precipitation limitations may be evidenced by the decreasing maximum rainfall intensities with increasing contributing area. However, the strong power-law relationship between $Q_{\mathrm{p}}$ and contributing area for all recurrence intervals indicates that $Q_{\mathrm{p}}$ is, in general, increasing predictably over the range of contributing areas used in this study. Even if precipitation limitations affect the shape of the curve, this single hypothesis does not account for all of the concavedown shape of each FEC suggesting that other mechanisms are important to creating the characteristic shape. However, it is important to note that the importance of each mechanism may be different for different locations.

\subsection{Climate variability in the NEXRAD data}

The results from comparing negative and positive MEI conditions in the UCRB and LCRB are generally consistent with ideas about ENSO and how it affects precipitation in the western US. In the LCRB, during negative MEI conditions, small, frequent storms have similar or slightly higher maximum rainfall intensities and $Q_{\mathrm{p}}$ values than during positive MEI conditions. This similarity between the two conditions may be explained by the balancing of increased winter moisture during El Niño in the southwestern US (Hidalgo and Dracup, 2003) and increased summer moisture through the strengthening of the NAM system and the convective storms it produces during La Niña conditions (Castro et al., 2001; Grantz et al., 2007). In general, the strengthening of the NAM may explain the higher maximum rainfall intensities and $Q_{\mathrm{p}}$ values during negative MEI conditions in the LCRB. Strengthening of the NAM may be due in part to the large temperature difference between the cool sea surface of the eastern Pacific Ocean and the hot land surface of the southwestern US and northwestern Mexico during La Niña conditions. The large temperature gradient increases winds inland, bringing the moisture associated with the NAM (Grantz et al., 2007). In the UCRB it is during negative MEI conditions, where the highest maximum rainfall intensities and $Q_{\mathrm{p}}$ values for all recurrence intervals occur. This suggests that the UCRB is affected by ENSO much like the northwestern US, where wetter winters are affiliated with La Niña and not El Niño conditions (Cayan et al., 1999; Hidalgo and Dracup, 2003). It is important to note that this comparison is of intensity rates and not total precipitated moisture so the MEI condition resulting in wetter conditions is not known.

In addition to the ENSO analysis, by investigating previous studies we see that, along with natural yearly precipitation variability, the 1996 to 2004 water years included many atmospheric river events (Dettinger, 2004; Dettinger et al., 2011). It is important that these events were included due to their ability to greatly increase winter precipitation in the UCRB and LCRB (Rutz and Steenburgh, 2012). Atmospheric river events (sometimes known as Pineapple Express events) can also be tied to major Pacific climate modes such as the ENSO (Dettinger, 2004; Dettinger et al., 2011), the Pacific Decadal Oscillation (PDO; Dettinger, 2004), and the North Pacific Gyre Oscillation (NPGO; Reheis et al., 2012) in southern California. Unfortunately, correlations between atmospheric river events are unknown and/or less clear for the interior western US. However, all three of these Pacific climate modes shifted during the 9-year study period in $\sim 1998$ to 1999 (Reheis et al., 2012), indicating that both positive and negative conditions of the ENSO, PDO, and NPGO exist in the NEXRAD products used in this study. 
The presence of distinct trends in maximum rainfallintensity and $Q_{\mathrm{p}}$ values calculated for negative and positive MEI conditions, as well as the information in the literature on atmospheric river events, indicates the NEXRAD products used in this study incorporate circulation-scale weather patterns. In addition, the patterns in maximum rainfall intensities and $Q_{\mathrm{p}}$ values during different MEI conditions agree with common understanding of the effects of ENSO on the western US and provide evidence that the data and methods used in this paper to analyze precipitation are reliable. This analysis shows that the NEXRAD products worked well in this location and that using radar-derived precipitation products may be useful for identifying precipitation and climatic trends in other locations where the FMAC method can be applied.

\section{Conclusions}

In this study we present the new FMAC method of calculating precipitation and flood discharges of a range of recurrence intervals using radar-derived precipitation estimates combined with a flow-routing algorithm. This method improves on the traditional FEC by assigning recurrenceinterval information to each value and/or curve. Also, instead of relying on stream-gauge records of discharge, this method uses up-to-date and spatially complete radar-derived precipitation estimates (in this case NEXRAD products) to calculate flood discharges using flow-routing algorithms. This study presents an alternative data source and method for floodfrequency analysis by calculating extreme (high recurrence interval) event magnitudes from a large sample set of magnitudes made possible by sampling the radar-derived precipitation estimates.

The FMACs for $Q_{\mathrm{p}}$ and $Q_{\mathrm{fd}}$ for the UCRB were similar to those produced for the LCRB. In general, all recurrenceinterval curves followed the same general trend, indicating that the mechanisms of precipitation and flood discharge are similar for the two basins. However, there were some differences between the two basins. Overall, there were larger differences between curves of different recurrence intervals for the UCRB than the LCRB, suggesting a larger range in maximum rainfall intensities, and therefore $Q_{\mathrm{p}}$ and $Q_{\mathrm{fd}}$, in the UCRB relative to the LCRB. For both the UCRB and LCRB the 50- and 100-year recurrence-interval curves for all precipitation and discharge FMACs were the most similar. This similarity may mean that although historical discharge records are short, having a 50-year record may not underestimate the 100-year flood as much as one might expect. Also, for $Q_{\mathrm{p}}$ and $Q_{\mathrm{fd}}$, low recurrence-interval values were slightly higher in the LCRB than in the UCRB. This relationship was opposite for high recurrence-interval values. This likely points to a general hydroclimatic difference between the two basins, with the LCRB receiving high-intensity storms annu- ally due to the NAM and the UCRB receiving more intense and rarer winter frontal storms.

Power-law relationships between maximum rainfall intensity, $Q_{\mathrm{p}}$, and contributing area were also found in this study. Maximum rainfall intensities decreased as a powerlaw function of contributing area with an average exponent of $-0.18 \pm 0.06$ for all recurrence intervals. $Q_{\mathrm{p}}$ values for all recurrence intervals increased as a power-law function of contributing area with an exponent of approximately $0.82 \pm 0.06$ on average. Based on the constant power-law relationship between $Q_{\mathrm{p}}$ and contributing area, the "gap" or characteristic concave-down shape of published FECs is likely not caused by precipitation limitations.

In general, the FMACs of $Q_{\mathrm{fd}}$ calculated in this study are lower than, and exceed, the published FECs for the LCRB at lower and higher contributing areas. All FMACs of $Q_{\mathrm{fd}}$ were positioned well below the US FECs except the UCRB 500-year FMAC, which approximated the US FECs during wet antecedent-moisture conditions. All FMACs of $Q_{\mathrm{fd}}$ for all moisture conditions in the LCRB closely approximated the same magnitudes as the published LCRB FEC, but exceeded it for larger contributing areas. The higher estimates of flood discharges at larger contributing areas may be the result of the difference of sampling methods and are likely not erroneous and may be proved true by future events.

Lastly, the approximately 9 years of NEXRAD products were found to be a good representation of climate in the CRB. This conclusion was made based on differences in precipitation between positive and negative ENSO conditions in both the UCRB and LCRB and additional data found in the literature. In general, the UCRB was found to have a hydroclimatic regime much like that of the northwestern US, where El Niño conditions result in lower maximum rainfall intensities and amounts and La Niña conditions result in higher maximum rainfall intensities. The LCRB showed a more complex trend with similar maximum rainfall intensities for both El Niño and La Niña conditions.

Here this method is applied to the UCRB and LCRB in the southwestern US, but could be applied to other regions of the US and the world with variable climate and storm types where radar-derived precipitation estimates are available. In this study we used set values for contributing area, drainage basin shape, time intervals of measurement, and recurrence intervals that can be changed based on the focus of future studies. However, it is also important to note that a number of assumptions were made in this study that simplified our analysis; most importantly, (1) space-for-time substitution, or regionalization, was used to increase the number of samples and assumed that observations were independent and sampled from the same distribution; (2) it was assumed that the time period length and the spatial and temporal sampling scales were sufficient to create a representative sample from the observations; and (3) it was assumed that similar floodgenerating and flow-routing mechanisms (and related variables such as runoff coefficients) were present in each basin 
regardless of size or location. These assumptions allowed us to form and apply the methods described here to our study area, but may not apply to all areas. Other variables such as snowpack, elevation, land use, and climate change that were not included in this study should be explored in conjunction with this methodology to better understand controls on precipitation and flooding. The absence of these elements from the method here may limit the application of this method to other locations.

Acknowledgements. This study was supported by the Jemez River Basin and Santa Catalina Critical Zone Observatory NSF grants EAR-0724958 and EAR-1331408. We would like to thank Vic Baker, Phil Pearthree, Peter Troch, and Katie Hirschboeck for helpful discussions and suggestions.

Edited by: P. Saco

Reviewed by: two anonymous referees

\section{References}

Baeck, M. L. and Smith, J. A.: Rainfall estimates by the WSR-88D for heavy rainfall events, Weather Forecast., 13, 416-436, 1998.

Baker, V. R.: Paleoflood hydrology and extraordinary flood events, J. Hydrol., 96, 77-99, 1987.

Brutsaert, W.: Review of Green's functions for linear open channels, J. Eng. Mech.-ASCE, 99, 1247-1257,1973.

Buishand, T. A.: Extreme rainfall estimation by combining data from several sites, Hydrolog. Sci. J., 36, 345-365, doi:10.1080/02626669109492519, 1991.

Burton Jr., G. A. and Pitt, R. E. (Eds.): Stormwater effects handbook: a toolbox for watershed managers, scientists, and engineers, Lewis Publishers, Boca Raton, Florida, 2001.

Cañon, J., González, J., and Valdes, J.: Precipitation in the Colorado River Basin and its low frequency associations with PDO and ENSO signals, J. Hydrol., 333, 252-264, 2007.

Castellarin, A.: Probabilistic envelope curves for design flood estimation at ungauged sites, Water Resour. Res., 43, W04406, doi:10.1029/2005WR004384, 2007.

Castellarin, A., Vogel, R. M., and Matalas, N. C.: Probabilistic behavior of a regional envelope curve, Water Resour. Res., 41, W06018, doi:10.1029/2004WR003042, 2005.

Castellarin, A., Merz, R., and Bloschl, G.: Probabilistic envelope curves for extreme rainfall events, J. Hydrol., 378, 263-271, 2009.

Castro, C. L., McKee, T. B., and Pielke Sr., R. A.: The relationship of the North American Monsoon to Tropical and North Pacific surface temperatures as revealed by observational analyses, J. Climate, 14, 4449-4473, 2001.

Cayan, D. R., Redmond, K. T., and Riddle, L. G.: ENSO and hydrologic extremes in the western United States, J. Climate, 12, 2881-2893, 1999.

Costa, J. E.: A comparison of the largest rainfall-runoff floods in the United States with those of the People's Republic of China and the World, J. Hydrol., 96, 101-115, 1987.
Crippen, J. R. and Bue, C. D.: Maximum flood flows in the conterminous United States, US Geological Survey Water Supply Paper 1887, US Geological Survey, Washington, D.C., USA, 1977.

Dalrymple, T.: Flood-frequency analyses, Manual of Hydrology: Part 3, US Geological Survery Water Supply Paper 1543, US Geological Survey, Washington, D.C., USA, p. 80, 1960.

Dettinger, M. D.: Fifty-two years of "Pineapple-Express" storms across the west coast of North America, PIER Energy-Related Environmental Research, CEC-500-2005-004, US Geological Survey, Scripps Institution of Oceanography for the California Energy Commission, La Jolla, California, USA, 2004.

Dettinger, M. D., Ralph, F. M., Das, T., Neiman, P. J., and Cayan, D. R.: Atmospheric rivers, floods, and the water resources of California, Water, 3, 445-478, 2011.

Enzel, Y., Ely, L. L., House, P. K., Baker, V. R., and Webb, R. H.: Paleoflood evidence for a natural upper bound to flood magnitudes in the Colorado River Basin, Water Resour. Res., 29, 2287-2297, 1993.

Etheredge, D., Gutzler, D. S., and Pazzaglia, F. J.: Geomorphic response to seasonal variations in rainfall in the Southwest United States, Geol. Soc. Am. Bull., 116, 606-618, 2004.

FEMA - Federal Emergency Management Agency: Modernizing FEMA's flood hazard mapping program: Recommendations for using future-conditions hydrology for the National Flood Insurance Program, Final Report, US Department of Homeland Security, Washington, D.C., USA, 2001.

Fulton, R. A., Breidenbach, J. P., Seo, D. J., Miller, D. A., and O'Bannon, T.: The WSR-88D algorithm, Weather Forecast., 13, 377-395, 1998.

Giannoni, F., Smith, J. A., Zhang, Y., and Roth, G. Hydrologic modeling of extreme floods using radar rainfall estimates, Adv. Water Resour., 26, 195-203, 2003.

Grantz, K., Rajagopalan, B., Clark, M., and Zagona, E.: Seasonal shifts in the North American Monsoon, J. Climate, 20, 1923 1935, 2007.

Henderson, F. M.: Some properties of the unit hydrograph, J. Geophys. Res., 68, 4785-4793, 1963.

Herschy, R.: The world's maximum observed floods, Flow Meas. Instrum., 13, 231-235, 2002.

Hershfield, D. M.: Rainfall Frequency Atlast of the United States for Durations from 30 minutes to 24 hours and periods from 1 to 100 years, US Weather Bureau Technical Paper No. 40, US Weather Bureau, Washington, D.C., USA, p. 65, 1961.

Hidalgo, H. G. and Dracup, J. A.: ENSO and PDO Effects on hydroclimatic variations of the Upper Colorado River Basin, J. Hydrometeorol., 4, 5-23, 2003.

Hosking, J. R. M. and Wallis, J. R.: The effect of intersite dependence on regional flood frequency analysis, Water Resour. Res., 24, 588-600, 1988.

Hosking, J. R. M., and Wallis, J. R.: Regional Frequency Analysis, Cambridge University Press, New York, p. 283, 2005.

House, P. K. and Hirschboeck, K. K.: Hydroclimatological and paleohydrological context of extreme winter flooding in Arizona, 1993, in: Storm-Induced Geologic Hazards: Case Histories from the 1992-1993 Winter in Southern California and Arizona, vol. XI, edited by: Larson, R. A. and Slosson, J. E., Geological Society of America Reviews in Engineering Geology, Boulder, Colorado, 1-24, 1997. 
Johnson, D., Smith, M., Koren, V., and Finnerty, B.: Comparing mean areal precipitation estimates from NEXRAD and rain gauge networks, J. Hydrol. Eng., 4, 117-124, 1999.

Kang, K. and Merwade, V.: Development and application of a storage-release based distributed hydrologic model using GIS, J. Hydrol., 403, 1-13, 2011.

Li, B.: Current status of weather radar data exchange, World Meteorological Organization Workshop on Radar Data Exchange, April 2013, 16.IV.2013, Exeter, UK, 2013.

Marani, M., Rinaldo, A., Rigon, R., Rodriquez-Iturbe, I.: Geomorphological width functions and the random cascade, Geophys. Res. Lett., 21, 2123-2126, 1994.

Mesa, O. J. and Mifflin, E. R.: On the relative role of hillslope and network geometry in hydrologic response, in: Scale Problems in Hydrology, edited by: Gupta, V. K., Rodriguez-Iturbe, I., and Wood, E. F., D. Reidel, Dordrecht, the Netherlands, 1-17, 1986.

Miller, A. J.: Flood hydrology and geomorphic effectiveness in the central Appalachians, Earth Surf. Proc., 15, 119-134, 1990.

Milly, P. C. D., Betancourt, J., Falkenmark, M., Hirsch, R. M., Kundzewicz, Z. W., Lettenmaier, D. P., and Stouffer, R. J.: Stationarity is dead: Whither water management?, Science, 319, 573-574, 2008.

Moody, T., Wirtanen, M., and Yard, S. N.: Regional relationships for bankfull stage in natural channels of the arid southwest, National Channel Design Inc., Flagstaff, AZ, 38 pp., 2003.

Morrison, J. E. and Smith, J. A.: Stochastic modeling of flood peaks using the generalized extreme value distribution, Water Resour. Res., 38, 1305, doi:10.1029/2001WR000502, 2002.

Moussa, R.: What controls the width function shape, and can it be used for channel network comparison and regionalization?, Water Resour. Res., 44, W08456, doi:10.1029/2007WR006118, 2008.

NOAA Atlas 14 Point Precipitation Frequency Estimates: http: //hdsc.nws.noaa.gov/hdsc/pfds/pfds_map_cont.html, last access: 8 June 2016.

NOAA HDSG: http://dipper.nws.noaa.gov/hdsb/data/nexrad/cbrfc_ stageiii.php, last access: 8 August 2014.

Ogden, F. L. and Julien, P. Y.: Runoff model sensitivity to radar rainfall resolution, J. Hydrol., 158, 1-18, 1994.

Parrett, C. and Johnson, D. R.: Methods for estimating flood frequency in Montana based on data through water year 1998, US Geological Survey Water-Resources Investigations Report 03-4308, US Geological Survey, Reston, Virginia, USA, 2003.

Parzen, E.: Nonparametric statistical data modeling, J. Am. Stat. Assoc., 74, 105-121, 1979.

Puente, C. E. and Sivakumar, B.: A deterministic width function model, Nonlin. Processes Geophys., 10, 525-529, doi:10.5194/npg-10-525-2003, 2003.

RadarEU: http://www.radareu.cz/, last access: 1 August 2014.

Reed, S. M. and Maidment, D. R.: Coordinate transformations for using NEXRAD data in GIS-based hydrologic modeling, J. Hydrol. Eng., 4, 174-182, 2006.

Reheis, M. C., Bright, J., Lund, S. P., Miller, D. M., Skipp, G., and Fleck, R. J.: A half-million-year record of paleoclimate from the Lake Manix Core, Mojave Desert, California, Palaeogeogr. Palaeocl., 365-366, 11-27, 2012.

Rinaldo, A., Marani, A., and Rigon, R.: Geomorphological dispersion, Water Resour. Res., 27, 513-525, 1991.
Rinaldo, A., Vogel, G. K., Rigon, R., and Rodriguez-Itrube, I.: Can one gauge the shape of a basin?, Water Resour. Res., 31, 11191127, 1995.

Rodriguez-Iturbe, I. and Rinaldo, A. (eds.): Fractal River Basins: Chance and Self-Organization, Cambridge University Press, New York, NY, USA, 2001.

Rodriguez-Iturbe, I. and Valdes, J. B.: The geomorphic structure of hydrologic response, Water Resour. Res., 15, 1409-1420, 1979.

Rosenberg, E. A., Clark, E. A., Steinemann, A. C., and Lettenmaier, D. P.: On the contribution of groundwater storage to interannual streamflow anomalies in the Colorado River basin, Hydrol. Earth Syst. Sci., 17, 1475-1491, doi:10.5194/hess-17-14752013, 2013.

Rutz, J. J. and Steenburgh, W. J.: Quantifying the role of atmospheric rivers in the interior western United States, Atmos. Sci Lett., 13, 257-261, doi:10.1002/as1.392, 2012.

Saco, P. M. and Kumar, P.: Kinematic dispersion effects of hillslope velocities, Water Resour. Res., 40, W01301, doi:10.1029/2003WR002024, 2004.

Sankarasubramanian, A. and Vogel, R. M.: Hydroclimatology of the continental United States, Geophys. Res. Lett., 30, 1363, doi:10.1029/2002GL015937, 2003.

Shedd, R. C. and Fulton, R. A.: WSR-88D precipitation processing and its use in National Weather Service hydrologic forecasting, in: Proceedings, Engineering Hydrology: Proceedings of the Symposium Sponsored by the Hydrology Division of American Society of Civil Engineers, San Francisco, California, USA, 844-848, 1993.

Sivapalan, M. and Bloschl, G.: Transformation of point rainfall to areal rainfall: Intensity-duration-frequency curves, J. Hydrol., 204, 150-167, 1998.

Smith, J. A. and Krajewski, W. F.: A modeling study of rainfall ratereflectivity relationships, Water Resour. Res., 29, 2505-2514, 1993.

Smith, J. A., Seo, D. J., Baeck, M. L., and Hudlow, M. D.: An intercomparison study of NEXRAD precipitation data, Water Resour. Res., 32, 2035-2045, 1996.

Soong, D. T., Ishii, A. L., Sharpe, J. B., and Avery, C. F.: Estimating flood-peak discharge magnitudes and frequencies for rural streams in Illinois, US Geological Survey Scientific Investigations Report 2004-5103, US Geological Survey, Reston, Virginia, USA, p. 162, 2004.

Stedinger, J. R., Vogel, R. M., and Foufoula-Georgiou, E.: Frequency Analysis of Extreme Events, in: Handbook of Hydrology, chap. 18, edited by: Maidment, D. R., McGraw-Hill, Inc. Washington, D.C., USA, 1993.

Troch, P. A., Smith, J. A., Wood, E. F., and de Troch, F. P.: Hydrologic controls of large floods in a small basin: central Appalachian case study, J. Hydrol., 156, 285-309, 1994.

USDA Geospatial Data Gateway: http://gdg.sc.egov.usda.gov, last access: 12 October 2016

Veneziano, D., Moglen, G. E., Furcolo, P., and Iacobellis, V.: Stochastic model of the width function, Water Resour. Res., 36, 1143-1157, 2000.

Vivoni, E. R., Entekhabi, D., Bras, R. L., and Ivanov, V. Y.: Controls on runoff generation and scale-dependence in a distributed hydrologic model, Hydrol. Earth Syst. Sci., 11, 1683-1701, doi:10.5194/hess-11-1683-2007, 2007. 
Vogel, R. M. and Fennesset, N. M.: Flow-duration curves I: New interpretation and confidence intervals, J. Water Resour. Bull., 31, 485-504, 1994.

Wallis, J. R., Schaefer, M. G., Barker, B. L., and Taylor, G. H.: Regional precipitation-frequency analysis and spatial mapping for 24-hour and 2-hour durations for Washington State, Hydrol. Earth Syst. Sci., 11, 415-442, doi:10.5194/hess-11-415-2007, 2007.
Wolman, M. G. and Costa, J. E.: Envelope curves for extreme flood events, J. Hydraul. Eng.-ASCE, 110, 77-78, 1984.

Xie, H., Zhou, X., Hendricks, J. M. H., Vivoni, E. R., Guan, H., Tian, Y. Q., and Small, E. E.: Evaluation of Nexrad Stage III precipitation data over a semiarid region, J. Am. Water Resour. As., 42, 237-256, 2006. 